\title{
Dual targeting of SREBP2 and ERRa by carnosic acid suppresses RANKL-mediated osteoclastogenesis and prevents ovariectomy-induced bone loss
}

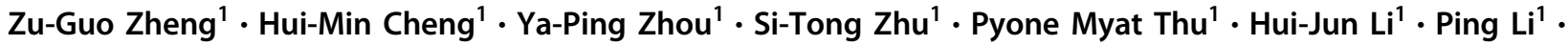 \\ Xiaojun $\mathrm{Xu}^{1,2}$
}

Received: 3 July 2019 / Revised: 13 December 2019 / Accepted: 16 December 2019 / Published online: 6 January 2020

(c) The Author(s), under exclusive licence to ADMC Associazione Differenziamento e Morte Cellulare 2020

\begin{abstract}
Osteoporosis develops because of impaired bone formation and/or excessive bone resorption. Several pharmacological treatment of osteoporosis has been developed; however, new treatments are still necessary. Cholesterol and estrogen receptor-related receptor alpha $(E R R \alpha)$ promote osteoclasts formation, survival, and cellular fusion and thus become high risk factors of osteoporosis. In this study, we identified that carnosic acid (CA) suppressed bone loss by dual-targeting of sterol regulatory element-binding protein 2 (SREBP2, a major regulator that regulates cholesterol synthesis) and ERR $\alpha$. Mechanistically, CA reduced nuclear localization of mature SREBP2 and suppressed de novo biogenesis of cholesterol. CA subsequently decreased the interaction between ERR $\alpha$ and peroxisome proliferator-activated receptor gamma coactivator 1-beta (PGC1 $\beta$ ), resulting in decreased the transcription activity of ERR $\alpha$ and its target genes expression. Meanwhile, CA directly bound to the ligand-binding domain of ERR $\alpha$ and significantly promoted its ubiquitination and proteasomal degradation. Subsequently, STUB1 was identified as the E3 ligase of ERR $\alpha$. The lysine residues (K51 and K68) are essential for ubiquitination and proteasomal degradation of ERR $\alpha$ by CA. In conclusion, CA dually targets SREBP2 and ERR $\alpha$, thus inhibits the RANKL-induced osteoclast formation and improves OVX-induced bone loss. CA may serve as a lead compound for pharmacological control of osteoporosis.
\end{abstract}

\section{Introduction}

Osteoclasts and osteoblasts continuously remodel bone tissue and maintain bone homeostasis by osteoclastic bone

These authors contributed equally: Zu-Guo Zheng, Hui-Min Cheng

Edited by M. Piacentini

Supplementary information The online version of this article (https:// doi.org/10.1038/s41418-019-0484-5) contains supplementary material, which is available to authorized users.

\section{Ping Li}

liping2004@126.com

$\checkmark$ Xiaojun $\mathrm{Xu}$

xiaojunxu2000@163.com

1 State Key Laboratory of Natural Medicines, China Pharmaceutical University, 210009 Nanjing, Jiangsu, China

2 Jiangsu Key Laboratory of Drug Discovery for Metabolic Diseases, China Pharmaceutical University, 210009

Nanjing, Jiangsu, China resorption and osteoblastic bone formation [1-3]. Osteoblasts are bone-forming cells that are differentiated from pluripotent mesenchymal stem cells [4]. Osteoblasts produce bone extracellular matrix, deposit calcium, and express osteoclastogenic factors to support bone formation [5]. Preosteoclasts differentiate from monocyte/macrophage lineage cells after stimulation by macrophage colonystimulating factor (M-CSF) and receptor activator of NF$\kappa B$ ligand (RANKL). Subsequently, preosteoclasts fuse and differentiate into mature multinucleated osteoclasts, leading to bone resorption [6]. The imbalance in bone remodeling caused by abnormal osteoclast differentiation may result in skeletal diseases, such as osteoporosis and osteopetrosis [7]. Smoking, drinking alcohol, and lower estrogen levels in postmenopausal women all results in increased osteoclast activity, leading to bone loss and osteoporosis. Menopause increases total cholesterol (TC) and low density-cholesterol (LDL-c) increase substantially [8]. Many clinical studies have shown that high cholesterol level deteriorates bone health [9-12], therefore, women, especially those during menopausal stage, have much higher rates of osteoporosis than men at any given age $[13,14]$, at least partially due to 
increased cholesterol. Some in vitro and in vivo studies indicated that osteoclasts formation, survival, and cellular fusion depend on cholesterol $[15,16]$. Cholesterol lowering drugs greatly mitigates osteoclasts differentiation and activity [17, 18], thus reduces osteoporosis-associated fracture risk [19], while the use of fibrates or other lipidlowering drugs that mainly affect total triglycerides is not related to a significantly decreased bone fracture risk [20], suggesting selective reduction of cholesterol might be sufficient to delay bone loss. Sterol regulatory element-binding protein 2 (SREBP2), a key transcription factor that specifically regulates cholesterol synthesis, was proved to regulate osteoclasts differentiation [21-23]. Moreover, recent study reported that nuclear factor of activated $\mathrm{T}$ cells 1 (NFATc1), a key genes required for mature osteoclast formation, is one target gene of SREBP2 [24]. Pharmacological inhibition of SREBP2 by fatostatin or anhydroicaritin protects bone mass by suppression of RANKL-mediated osteoclasts differentiation [22, 23]. Together, SREBP2 is considered as a new therapeutic target in osteopenic disorders, such as osteoporosis.

Estrogen receptor-related receptor alpha (ERR $\alpha)$, one of ERR family members (ERR $\alpha, E R R \beta$, and ERR $\gamma$ ), is one of the first identified orphan nuclear receptors. ERR $\alpha$ and the ERs share high amino acid sequence similarity (68\%) in the DNA-binding domain and a moderate similarity (36\%) in other parts of the proteins, such as the ligand-binding $\mathrm{E}$ domain [25]. ERR $\alpha$ coordinates peroxisome proliferatoractivated receptor gamma coactivator 1-beta (PGC1 $\beta$ ) to enhance mitochondrial biogenesis and osteoclast function. In recent years, several groups have reported that ERR $\alpha$ regulates skeletal remodeling by controlling osteoclastogenesis [26-28]. In osteoclastogenesis, ERR $\alpha$ was identified as a pro-osteoclastic factor in vivo, and osteopetrosis was exhibited in the ERR $\alpha$ knockout mice. Concomitantly, osteoclastogenesis was significantly disturbed when ERR $\alpha$ was knocked down in vitro [29]. Moreover, ERR $\alpha$ was also implicated in osteoclasts mobility and actin cytoskeletal organization by regulating the osteopontin-integrin b3 chain-activated c-src (phosphorylated at the Tyr416) pathway causing the disruption of the specific actin structure implicated in osteoclast adhesion, migration, and invasion [30]. These reports suggest that ERR $\alpha$ is a therapeutic target for osteoporosis [26]. Interestingly, a recent study reports that cholesterol was identified as an endogenous $\mathrm{ERR} \alpha$ agonist [31]. Considering the interdependence of cholesterol and ERR $\alpha$, we reasoned that dual-targeting SREBP2 and ERR $\alpha$ might be an ideal strategy to treat osteoporosis.

Carnosic acid (CA) is a phenolic acid compound first found in Salvia officinalis L., with $\sim 3 \%$ weight content in air-dried leaves. CA exhibited potent anti-oxidation and anti-ageing effects and is widely used for treating obesity, cardiovascular diseases, and cancer [32]. However, there is no report on the treatment of osteoporosis with CA. In this study, we found CA suppressed SREBP2 activity and inhibited the osteoclasts formation. Mechanistically, CA directly bound to ERR $\alpha$ and promoted its degradation. All together, we discovered a dual-targeting compound against SREBP2 and ERR $\alpha$ with excellent antiosteoporosis effect.

\section{Materials and methods}

\section{Materials}

CA was purchased from Shanghai U-sea Bio-tech co., Ltd (Shanghai, China). 3-(4, 5-dimethylthiazol-2-yl)-2, 5diphenyltetrazoliumbromide (MTT), cholesterol, filipin, 25hydroxycholesterol, and 4,6-diamidino-2-phenylindole (DAPI) were purchased from Keygen Biotech (Nanjing, China). RANKL, M-CSF were from R\&D Biosystems (Minneapolis, USA). The TRAP staining kit was from SigmaAldrich (St. Louis, USA). DMEM, $\alpha$-MEM and FBS (fetal bovine serum) was from GIBCO (Grand Island, New York, USA); rhodamine-labeled phalloidin (RP) from YEASEN (Shanghai, China); MG-132 was from MedChem Express (Shanghai, China). Cycloheximide was purchased from Selleckchem (Shanghai, China). Anti-ERR $\alpha$ (catalogue no. ab76228), anti-PGC1 $\beta$ (catalogue no. ab176328), and antiSREBP2 (catalogue no. ab30682) antibodies were purchased from Abcam (Cambridge, UK), Anti-HA (catalogue no. AE008) and anti-Histone H3 (catalogue no. A2348) antibodies were purchased from ABclonal Technology (Wuhan, Hubei, China). SREBP1 (catalogue no. sc-8984) antibody was from Santa Cruz (Dallas, TX, USA). His-ERR $\alpha$, HisERR $\alpha$ (Q390A, G793A mutation), His-ERR $\alpha$ (6KA mutation), His-ERR $\alpha$ (K14A), His-ERR $\alpha$ (K24A), His-ERR $\alpha$ (K51A), His-ERR $\alpha$ (K68A), His-ERR $\alpha$ (K189A), His-ERR $\alpha$ (K208A), Flag-NEDD4, Flag-BARD1, Flag-MDM2, FlagSTUB1, Flag-SUMPF1 plasmids were constructed by gene synthesis and site-directed mutagenesis. siRNA MDM2\#1 (CCUACUGAUGGUGCUGUAATT), MDM2\#2 (CCUGC UUUACAUGUGCAAATT), STUB1\#1 (GGAGAUGGAG AGCUAUG AUTT), STUB1\#2 (CCAAGCACGACAAGU ACAUTT) were purchased from GenePharma (Shanghai, China). Scrambled siRNA (UUCUCCGAACGUGUCACG UTT) was used as control.

\section{Cell culture}

The murine monocytic cell line RAW264.7, MC3T3-E1, HeLa, MDA-MB-231, MCF7, 293T (ATCC, VA) was cultured in a humid incubator with $5 \% \mathrm{CO}_{2}$ at $37^{\circ} \mathrm{C}$, and maintained in DMEM containing 10\% FBS, 100 units $/ \mathrm{ml}$ penicillin and $100 \mu \mathrm{g} / \mathrm{ml}$ streptomycin. The primary mature 
osteoclasts were generated from BMMs (bone marrowderived monocytes) as described [33]. Briefly, BMMs were isolated from tibiae and femurs from 6-week-old C57BL6 mice. BMMs $\left(1-2 \times 10^{5}\right)$ were seeded into a well of a $24-$ well plate and $1 \times 10^{6}$ BMMs were seeded into a well of a six-well plate. The cells were cultured in $\alpha$-MEM containing $10 \%(\mathrm{v} / \mathrm{v})$ FBS, $100 \mathrm{ng} / \mathrm{ml}$ RANKL and $30 \mathrm{ng} / \mathrm{ml} \mathrm{M-}$ $\mathrm{CSF}$ at $37^{\circ} \mathrm{C}$ in a humidified atmosphere containing $5 \%$ $\mathrm{CO}_{2}$ for $4-6$ days.

\section{Viability assay}

Cell viability was detected by the MTT assay. Briefly, RAW264.7 cells were seeded at the density of $2 \times 10^{4}$ cells/ well into 96-well plates. After $24 \mathrm{~h}$, cells were treated with CA as indicated for 3 days. After the treatment, MTT $(5 \mathrm{mg} / \mathrm{ml})$ was added and cells were incubated for $4 \mathrm{~h}$. The cytotoxicity of CA was determined by microplate reader (Multiskan FC).

\section{Western blotting}

RAW264.7 cells were washed with ice-cold PBS and dissolved with RIPA buffer (50 mM Tris - HCl, pH 8.0, $150 \mathrm{mM}$ $\mathrm{NaCl}, 1 \%$ Nonidet P-40, $0.5 \%$ sodium deoxycholate, $0.1 \%$ SDS, $1 \mathrm{mM}$ EDTA and protease inhibitors). Whole-cell extracts were separated by SDS-PAGE and transferred into polyvinylidene fluoride membranes. The membranes were blocked with 5\% skim milk in TBS with Tween-20 (PBST). Then, anti-SREBP2 antibody (Abcam, USA) or antiactin antibody (Beyotime Biotechnology, China) was bound overnight at $4{ }^{\circ} \mathrm{C}$. After washing with TBST, HRP-conjugated secondary antibody (Beyotime Biotechnology, China) was bound for $1 \mathrm{~h}$ at room temperature. Immunoreactive signals were detected with Chemi-Lumi One Ultra (Tanon, China).

\section{Quantitative RT-PCR}

Total RNA was extracted from cells using TRIzol reagent (Vazyme, China) according to the manufacturer's instructions. RNA concentrations were equalized and converted into cDNA using a kit (Hiscript II reverse transcriptase, Vazyme, Nanjing, China). Gene expression was measured in a LightCycler ${ }^{\circledR} 96$ System (Roche, Basel, Switzerland) using SYBR-green dyes (Vazyme, China). Gene expression was normalized to GAPDH. The sequences of primers used in the experiments are listed in Supplemental Table 1.

\section{Osteoclast formation and TRAP staining}

Monocyte/macrophage cell line RAW264.7 $\left(2 \times 10^{3}\right.$ cells/ well) were cultured in 96-well plates in DMEM with $10 \%$ FBS, $100 \mathrm{ng} / \mathrm{ml}$ of RANKL for $24 \mathrm{~h}$. Then, cells were treated with DMEM containing $10 \%$ FBS, $100 \mathrm{ng} / \mathrm{ml}$ of RANKL in the presence or absence of CA for 4 days. After 4 or 5 days of culture, the cells were fixed and stained for tartrate-resistant acid phosphatase (TRAP) activity. Multinucleated ( $>3$ nuclei) TRAP-positive cells were calculated.

\section{Actin-ring formation assay}

After stimulation with M-CSF (30 ng/ml) and RANKL (30 $\mathrm{ng} / \mathrm{ml}$ ), we fixed the cells with $4 \%$ paraformaldehyde (PFA) for $10 \mathrm{~min}$ and washed three times with PBS. Then, the cells were incubated with TRITC-phalloidin (Sigma) for $1 \mathrm{~h}$ followed with DAPI staining (Sigma) for $10 \mathrm{~min}$.

\section{Filipin staining}

Cells were seeded into 24-well plates at the density of $5 \times$ $10^{4}$ cells/well and maintained in $5 \% \mathrm{CO}_{2}$ at $37{ }^{\circ} \mathrm{C}$ for $24 \mathrm{~h}$. Then, cells were transfected with siRNA for $48 \mathrm{~h}$. After that, cells were incubated in medium D for $24 \mathrm{~h}$, or medium D with the indicated concentrations of CA for $16 \mathrm{~h}$. After the treatment, $50 \mu \mathrm{g} / \mathrm{ml}$ fillipin were used to stain the treated cells for $30 \mathrm{~min}$ at $24^{\circ} \mathrm{C}$. The filipin stained cells were analyzed with EVOS FL Auto microscope (Life technologies). The quantification of the cellular neutral lipids or cholesterol was analyzed by Image-Pro Plus.

\section{Triacylglycerol and cholesterol measurement}

For measurement of intracellular total triacylglycerol (TG) and total cholesterol (TC), the cells were cultured in sixwell plates and collected in $1 \mathrm{ml}$ PBS. One hundred microliters of the total cell suspension was transferred into a new tube and centrifuged at $1000 \times g$ for $5 \mathrm{~min}$ at $4{ }^{\circ} \mathrm{C}$. Then, this portion of the cells were lysed in lysis buffer (RIPA lysis buffer) and used for protein quantification. The remaining cell suspension was used for lipid extraction. After centrifugation at $1000 \times g$ for $5 \mathrm{~min}$ at $4{ }^{\circ} \mathrm{C}$, the collected cells were mixed with $1 \mathrm{ml}$ of chloroform/methanol $(2: 1, \mathrm{v} / \mathrm{v})$ adequately on a shaker for $3 \mathrm{~h}$ at $24^{\circ} \mathrm{C}$. Then, $500 \mu \mathrm{l} \mathrm{NaCl}(0.1 \mathrm{M})$ was added into each reaction tube and mixed thoroughly, followed by centrifugation at $3700 \mathrm{rpm}$ for $10 \mathrm{~min}$. The lower organic phase was transferred and evaporated to dryness. The residual liquid was resuspended in $50 \mu \mathrm{l}$ of $1 \%$ Triton X-100 in absolute ethanol, and the concentrations of lipids were measured using the TG and TC determination kit according to the manufacturer's instructions, respectively (Kehua, Shanghai, China).

\section{Microscale thermophoresis analysis}

CA were titrated in different concentrations to purified recombinant human ERR $\alpha$ and mutation proteins. The 
reaction was performed in $50 \mathrm{mM}$ Hepes, $50 \mathrm{mM} \mathrm{NaCl}$, $0.01 \%$ Tween-20, and $2 \mathrm{mM} \mathrm{MgCl}_{2}$. Then, the samples were incubated at room temperature for $5 \mathrm{~min}$ before analyzing by microscale thermophoresis (MST). A NanoTemper Monolith Instrument (NT.115) was used for measuring thermophoresis. In this instrument, an infra blue Laser (IB Laser) beam couples into the path of light (i.e., fluorescence excitation and emission) with a dichroic mirror and is focused into the sample fluid through the same optical element used for fluorescence imaging. The IB laser is absorbed by the aqueous solution in the capillary and locally heats the sample with a $1 / \mathrm{e}^{2}$ diameter of $25 \mu \mathrm{m}$. Up to $24 \mathrm{~mW}$ of laser power where used to heat the sample, without damaging the biomolecules. To analyze the thermophoresis of a sample, $10 \mu \mathrm{l}$ of sample solution were transferred in a glass capillary (NanoTemper, hydrophilic treated). Thermophoresis of the protein in presence of varying concentrations of compound was analyzed for $30 \mathrm{~s}$. Measurements were performed at room temperature and standard deviation was calculated from three independent experiments.

\section{Immunofluorescence}

In brief, cells were fixed with $4 \%$ PFA for $15 \mathrm{~min}$, and then permeabilized with $0.1 \%$ Triton X-100 in PBS for $15 \mathrm{~min}$. after blocking in 3\% BSA for $1 \mathrm{~h}$, the cells were incubated with the primary and corresponding fluorophore-conjugated secondary antibodies. Confocal images were captured with an LSM 710 confocal microscope (ZEISS). The merged pictures were generated by LSM 7 IMAGE browser (Zeiss, Germany).

\section{Reporter gene assay}

RAW264.7 cells were transfected with luciferase reporter plasmids containing ERR $\alpha, \mathrm{ERR} \beta, \mathrm{ERR} \gamma$, or Nur77 enhancers respectively using $\mathrm{X}$-tremeGENE HP DNA Transfection Reagent (Roche) for $24 \mathrm{~h}$. $\beta$-galactosidase expression plasmid was co-transfected with luciferase reporters as an internal control. Cells were then exposed to different concentrations of CA. Cells were lysed in $100 \mu \mathrm{l}$ lysis buffer sufficiently on a shaker for $40 \mathrm{~min}$ at room temperature. Fifty microliters of the total cell suspension was transferred into a 96-well white plate (Perkin Elmer) for luciferase activity detection. The remaining cell suspension was tested for $\beta$-galactosidase activity using a $\beta$-Gal reporter gene assay kit (Beyotime) according to instructions of the manufacturer. The luciferase activity was measured immediately after adding $50 \mu \mathrm{l}$ luciferase substrates with a microplate reader and the intensity of $\beta$-Gal was also measured as the internal control.

\section{Animal experiment}

The laboratory animal facility in the animal center has been accredited by Association for Assessment and Accreditation of Laboratory Animal Care International. All experiments and animal care in this study were conducted in accordance with the Provision and General Recommendation of Chinese Experimental Animals Administration Legislation and approved by the Science and Technology Department of Jiangsu Province (SYXK (SU) 2016-0011). Female C57BJ/6L mice (SPF grade, 8 weeks old, 20-22 g) were purchased from Nanjing University (Nanjing, China). The animals were kept under a consistent temperature $\left(24^{\circ} \mathrm{C}\right)$ with $12 \mathrm{~h} \mathrm{light/dark} \mathrm{cycle}$ and fed standard food pellets with the access to sterile water ad libitum. Mice were ovariectomized (OVX) under ketamine $(120 \mathrm{mg} / \mathrm{kg}) / x y l a z i n e ~(16 \mathrm{mg} / \mathrm{kg})$ anesthesia. Seven days after ovariectomy, mice were randomly and blindingly divided into five groups $(n=12 /$ group $)$ and receive daily intragastric administration for 16 weeks: sham operated mice (Sham), ovariectomized mice treated with vehicle (OVX), OVX mice treated with $0.1 \mathrm{mg} / \mathrm{kg}$ E2 $(\mathrm{OVX}+\mathrm{E} 20.1 \mathrm{mg} / \mathrm{kg}), \mathrm{OVX}$ mice treated with $30 \mathrm{mg} / \mathrm{kg}$ $\mathrm{CA}(\mathrm{OVX}+\mathrm{CA} 30 \mathrm{mg} / \mathrm{kg})$, and OVX mice treated with $60 \mathrm{mg} / \mathrm{kg}$ CA $($ OVX + CA $60 \mathrm{mg} / \mathrm{kg})$.

\section{Microcomputed tomography $(\mu \mathrm{CT})$ analysis}

Tibias were fixed with $70 \%$ ethanol and subjected to $\mu \mathrm{CT}$ analysis using a SkyScan 1176 system (Bruker, Germany) with an isotropic voxel size of $6 \mu \mathrm{m}$ for trabecular analyses according to the manufacturer's instructions and the guidelines of the American Society for Bone and Mineral Research (ASBMR). Two hundred slices of proximal tibial metaphysis starting at $0.6 \mathrm{~mm}$ from the end of the growth plate were scanned and analyzed. Threedimensional reconstructions were generated and analyzed according to the manufacturer's instructions and the ASBMR guidelines.

\section{Bone histomorphometry}

For TRAP staining, tibias were fixed in $70 \%$ ethanol for 3 days, and the nondecalcified bones were embedded in methyl methacrylate. Longitudinal 5- $\mu$ m-thick sections were cut on a microtome (Leica RM2255, Leica Microsystems, Germany) and subjected to TRAP staining using a TRAP Stain kit (Sigma, USA) according to the manufacturer's protocol. Histomorphometry of the secondary spongiosa was performed with the OsteoMeasure analysis system (OsteoMetrics, USA) at 200-fold magnification according to the ASBMR guidelines. 


\section{Immunohistochemistry}

Immunohistochemistry was carried out using 3- $\mu$ m-thick sections fixed in $4 \%$ PFA. After deparaffinization, rehydration, and antigen retrieval, sections were incubated in blocking buffer containing 10\% normal goat serum in PBS. Sections were incubated with described antibodies followed by washing and incubated with HRP-tagged goat anti-rabbit secondary antibody. Samples were subsequently rinsed in wash buffer and incubated in diaminobenzidine (Sigma, St. Louis, MO) for $5 \mathrm{~min}$ and counterstained in hematoxylin. Tissue slides were scored in a blinded fashion. No staining was observed with negative control rabbit anti-IgG antibody. The images were measured blindly by one observer using Image-Pro Plus (Media Cybernetics, Silver Spring, USA).

\section{Statistical analysis}

All data are expressed as the means standard error. The comparisons between groups were made using one-way ANOVA (Tukey's multiple comparisons test). The significance of differences between two groups was determined using Student's unpaired $t$ test. Differences with $p<0.05$ were considered to be statistically significant.

\section{Results}

\section{CA is identified as an inhibitor for both SREBP and osteoclast formation}

In our previous work, we screened a number of SREBPs inhibitors from a small molecule pool containing about 400 natural products using a reporter genes assay [8] (Fig. S1A). To identify whether these SREBPs inhibitor suppresses osteoclasts formation, RAW264.7 cells, a murine macrophage cell line, were treated with RANKL to differentiate into multinuclear TRAP-positive osteoclast-like cells [34]. Thirteen out of twenty-two SREBPs inhibitors suppressed RANKL-induced osteoclast-like cells formation (Fig. S1B, C). CA (Fig. S1D) exhibited the strongest activity to inhibit osteoclastogenesis (Fig. S1B, C). Meanwhile, CA did not obviously affect the cell viability of RAW264.7 cells or BMMs, even at the dose of CA up to $60 \mu \mathrm{M}$ (Fig. S1E). Thus, CA was selected for further studies.

\section{CA suppresses RANKL-induced osteoclast differentiation and function}

To determine the effects of CA on osteoclastogenesis, RAW264.7 and primary BMMs were used. In the solvent treated group, we observed the formation of TRAP-positive multinucleated osteoclasts in both BMMs (Fig. 1a, b) and RAW264.7 cells (Fig. S2A, B). The formation of osteoclasts was inhibited following the $\mathrm{CA}$ treatment in a concentration-dependent manner (Figs. 1a, b and S2A, B). The osteoclasts area and TRAP intensity were also dose dependently decreased (Figs. 1a, b and S2A, B) treated with CA. We next detected the differentiation process of BMMs or RAW264.7 cells with RANKL stimulation. Treatment with CA during the 1-3 days of differentiation obviously inhibited RANKL-induced osteoclasts differentiation (Figs. 1c, d and S2C, D). In comparison, if CA was added at later stage (day 5), it only slightly reduced the osteoclasts number, osteoclasts area and TRAP intensity (Figs. 1c, d and S2C, D). These data suggested that CA inhibited RANKL-induced osteoclasts differentiation at early stage.

To further assess the effects of CA on osteoclastogenesis, differentiated BMMs and RAW264.7 cells by RANKL treatment formed obvious actin-ring structures as stained with TRITC-phalloidin (Figs. 1e and S2E). In comparison, the number and size of actin ring were obviously reduced by CA treatment dose dependently (Figs. 1e and S2E). The expression of the osteoclastogenesis marker genes, such as acid phosphatase (Acp5), cathepsin $\mathrm{K}, T R A P$, Nuclear factor of activated $\mathrm{T}$ cells, cytoplasmic $1(N F A T c 1)$, and cellular oncogene fos $(C-F o s)$, was significantly inhibited by CA (Figs. 1f and S2F). Next, we assessed the effect of CA on osteoblasts formation and mineralization in vitro. The results showed that CA treatment did not affect the cell viability of osteoblasts (Fig. S3A) and did not influence the expression of the osteogenesis-related genes, such as alkaline phosphatase, type 1 collagen, osteocalcin, runt-related transcription factor 2, and Osteoprotegerin (Fig. S3B-F). Taken together, these in vitro data suggested that CA inhibited osteoclastogenesis.

\section{CA improves ovariectomy-induced bone loss by inhibiting osteoclast activity}

To evaluate the antiosteoporosis effect of CA in vivo, mice were either sham operated or OVX, and then were treated with CMC-Na, estradiol valerate (E2, $0.1 \mathrm{mg} / \mathrm{kg}$ ) or CA (30, $60 \mathrm{mg} / \mathrm{kg}$ ) for 16 weeks. There were no obvious adverse events recorded after the OVX procedure or the subsequent treatment with $\mathrm{CA}$. The body weight was significantly decreased in CA and E2 treatment group (Fig. 2a). After 16 weeks of CA administration, the levels of serum alkaline phosphatase, bone gla protein, serum 1 collagen crosslinked c-terminal peptide (CTX-1), and TRAP (strACP) increased in the ovariectomized mice, similar to the effect of E2 (Fig. 2b-e). The level of the blood calcium did not change in the ovariectomized and CA-treated mice (Fig. 2f). Treatment with CA $(60 \mathrm{mg} / \mathrm{kg})$ or E2 significantly reversed the blood phosphorus level in ovariectomized mice (Fig. 2g). 
Fig. 1 CA inhibits RANKL-

induced osteoclastogenesis and bone resorption without cytotoxic effects in vitro. a TRAP-positive osteoclast treated with indicated concentrations of CA followed by stimulation with $100 \mathrm{ng} / \mathrm{ml}$ RANKL and $30 \mathrm{ng} / \mathrm{ml} \mathrm{M}-\mathrm{CSF}$ for 7 days. b Quantification of area of osteoclasts, TRAPpositive multinuclear cells, and TRAP intensity. c BMMs were seeded and treated with $15 \mu \mathrm{M}$ CA for the indicated days during osteoclastogenesis.

d Quantification of area of osteoclasts, TRAP-positive multinuclear cells, and TRAP intensity. e BMMs were incubated with or without 100 $\mathrm{ng} / \mathrm{ml}$ RANKL and $30 \mathrm{ng} / \mathrm{ml} \mathrm{M}$ CSF, followed by treatment with indicated concentration of CA.

Cells were fixed and stained for F-actin (left). Osteoclasts having actin rings were counted (right). f BMMs cells were incubated with or without $100 \mathrm{ng} / \mathrm{ml}$ RANKL and $30 \mathrm{ng} / \mathrm{ml} \mathrm{M-CSF}$, followed by treatment with indicated concentration of CA for $96 \mathrm{~h}$. RT-qPCR ( $n=3$ biological replicates) was used to assess relative mRNA expression levels of indicated genes. Bars represent means \pm SD. $* p<0.05, * * p<0.01$, $* * * p<0.005$.
A

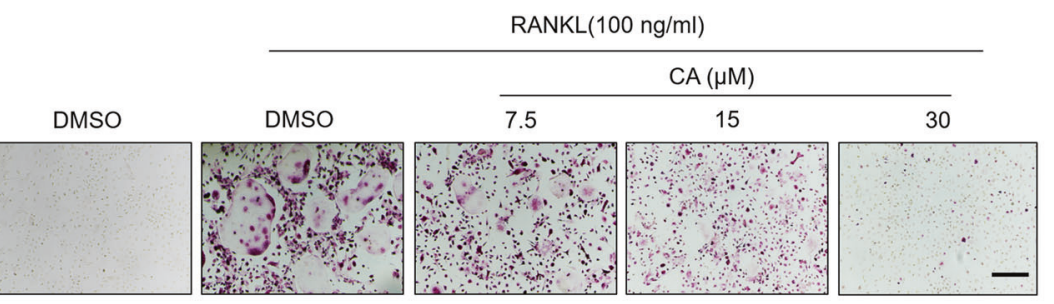

B
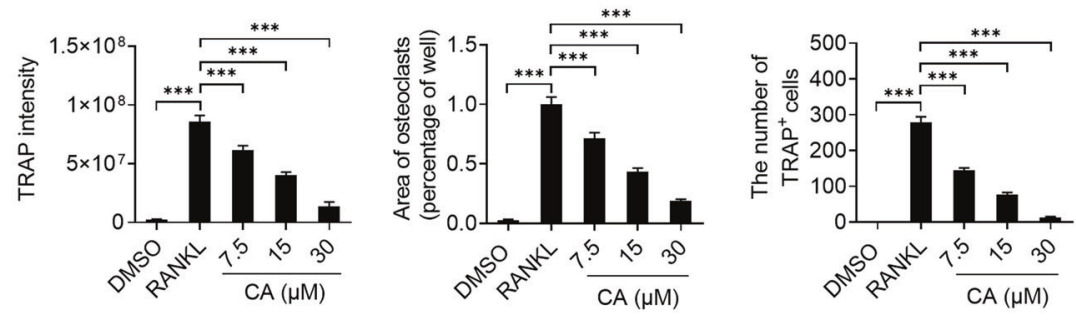

C

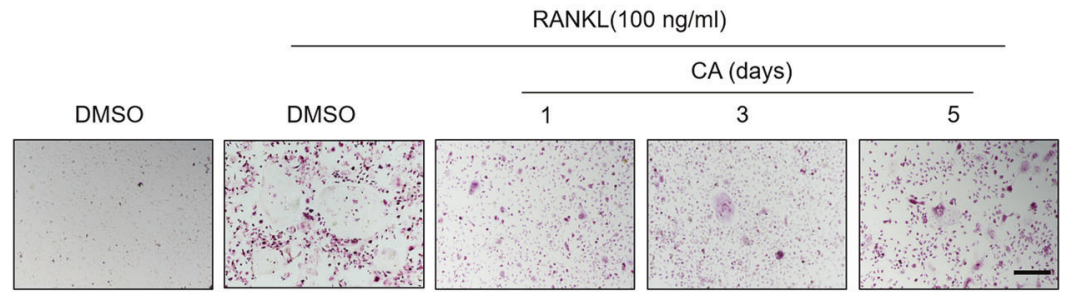

D

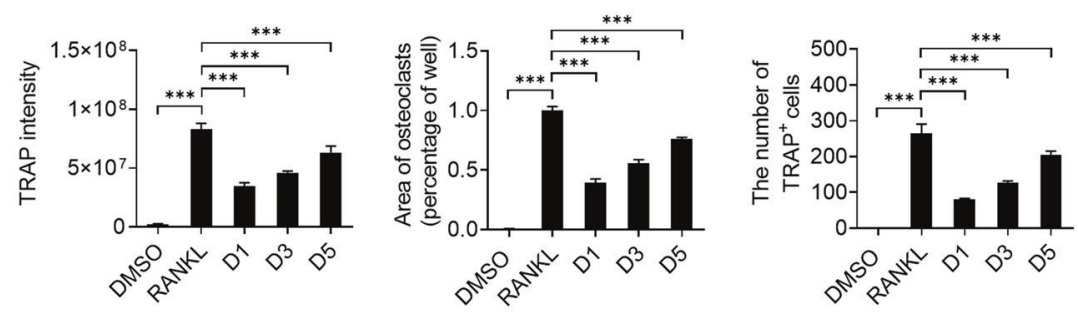

E

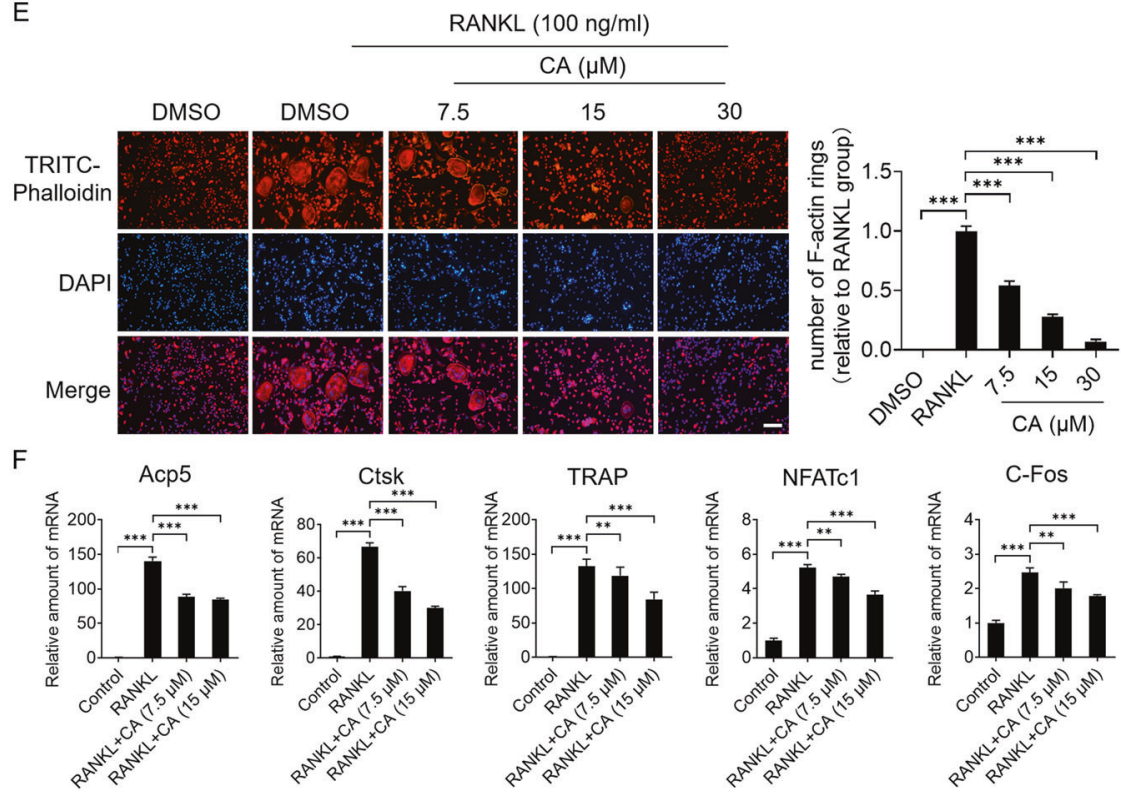

To evaluate the effects of $\mathrm{CA}$ on bone mass loss in ovariectomized mice, the tibiae of mice were then collected for $\mu \mathrm{CT}$ analysis. Representative 3D reconstructions of proximal tibial trabecular bone showed that $\mathrm{CA}$ treatment protected the OVX mice from bone loss (Fig. 2h), as shown by increased bone mineral density (BMD), bone 
A

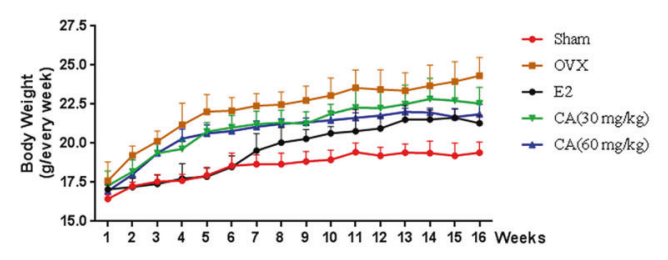

D

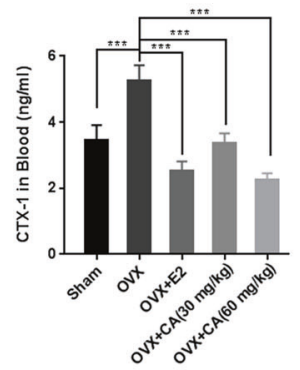

${ }^{H}$

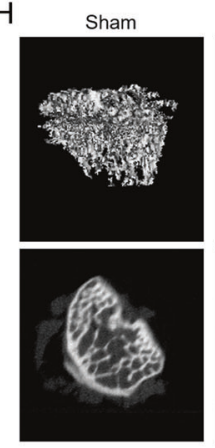

J
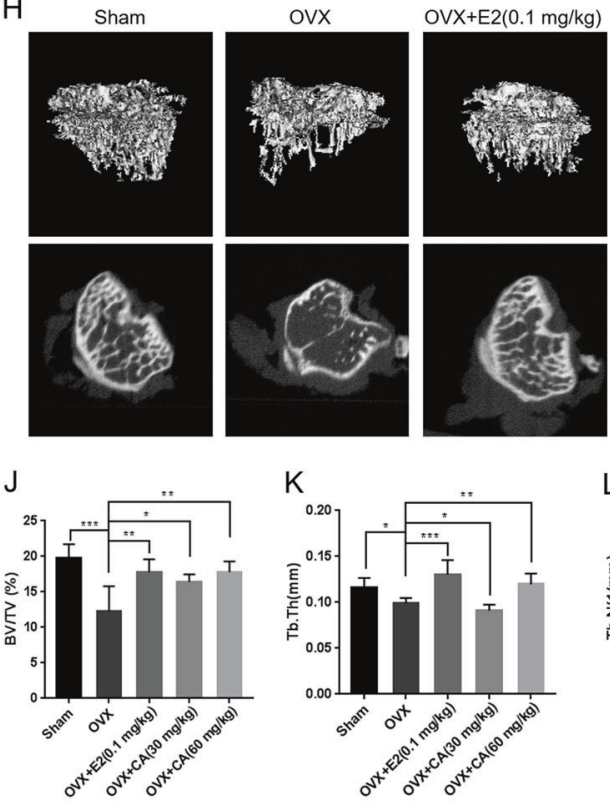

K

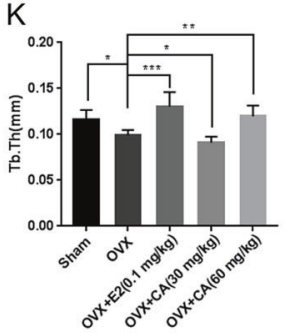

B

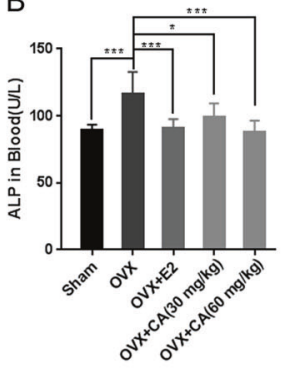

$\mathrm{F}$

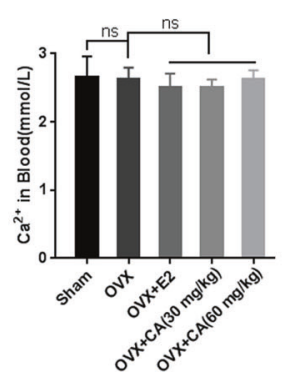

C

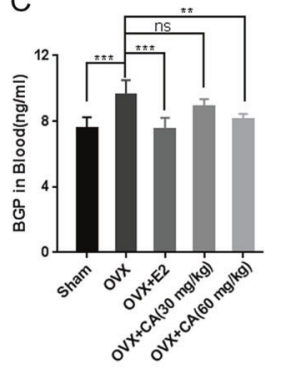

G

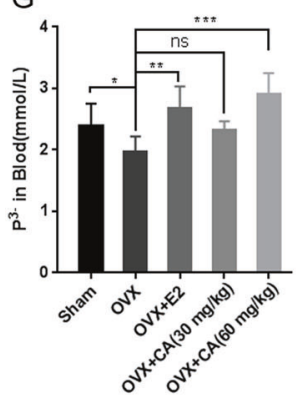

I

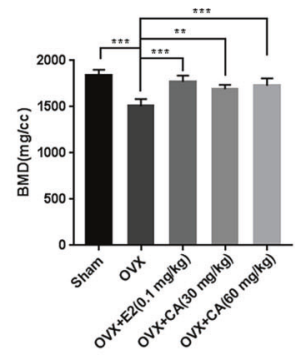

N

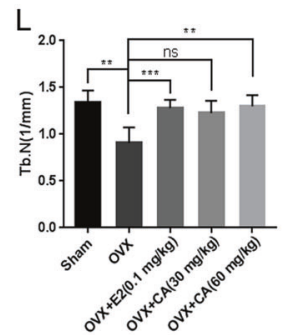

M

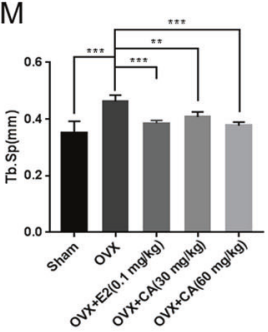

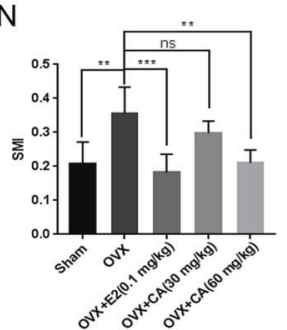

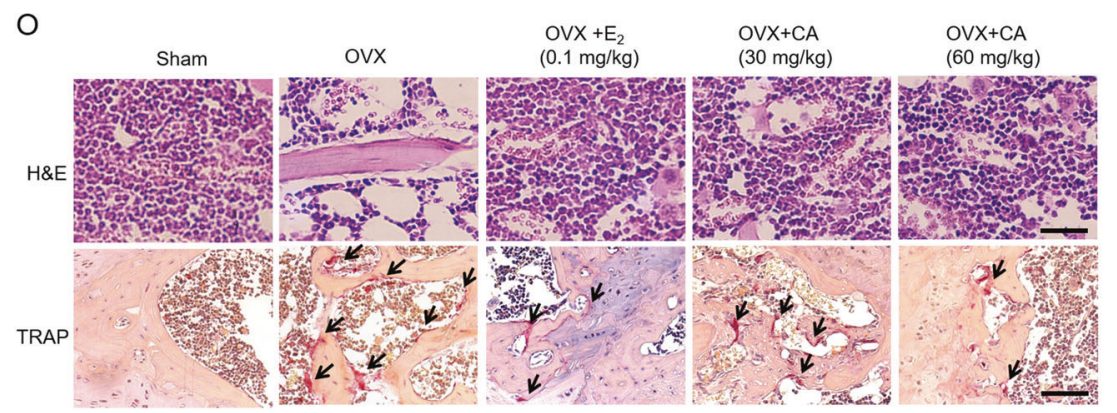

$\mathrm{P}$

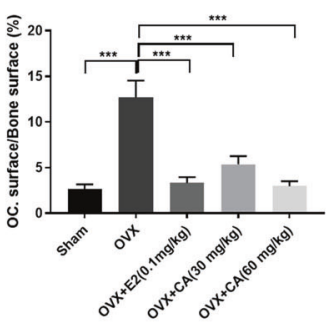

volume/tissue volume, trabecular thickness, trabecular number (Fig. 2i-1). Furthermore, trabecular spacing and structure model index were significantly reduced in the OVX $+\mathrm{CA}$ group compared with the OVX control group (Fig. 2m, n). These results indicated that $\mathrm{CA}$ protected against ovariectomy-induced bone loss. Then, the histomorphometric 
Fig. 2 CA improves blood biochemical indicators in OVX-induced osteoporotic mice. The fixed vertebral bodies of OVX mice were divided into four groups, 12 mice/group. The mice were treated E2 $(0.1 \mathrm{mg} / \mathrm{kg})$ or CA $(30,60 \mathrm{mg} / \mathrm{kg})$ for 16 weeks. a Body weight. b-g Effect of CA on blood ALP, BGP, CTX-1, strACP, calcium, and phosphorus. $\mathbf{h}$ CA suppressed bone loss in an OVX-induced bone loss model. Representative reconstructed 3D $\mu \mathrm{CT}$ images of proximal tibia in mice treated with CMC-Na, or E2 $(0.1 \mathrm{mg} / \mathrm{kg}$ ) or CA (30 or $60 \mathrm{mg} / \mathrm{kg}$ ). i-n Quantitative $\mu \mathrm{CT}$ analysis of trabecular structure in mice of each group. o H\&E and TRAP staining, respectively, of the vertebral body sections (black arrows, TRAP-positive cells). p OcS/BS $(\%)$ in treatment groups. Bars represent means \pm S.D., $n=12 /$ group, $* p<0.05, * * p<0.01$, and $* * * p<0.001$ vs control.

analyses of proximal tibial trabecular bones by TRAP staining were also performed to further confirm the effect of CA. Consistent with the $\mu \mathrm{CT}$ results, the osteoclasts surface/bone surface was decreased in CA-treated OVX mice (Fig. 2o, p). These results suggest that CA protects against OVX-induced bone loss by inhibiting osteoclasts formation.

\section{CA decreases cholesterol level by inhibiting SREBP2 activity in RANKL-induced osteoclasts}

It has been demonstrated that CA promotes the degradation of mature form of SREBP2 via the $26 \mathrm{~S}$ proteasome in liver cells, thus inhibits the hepatic de novo lipogenesis, especially, the synthesis of cholesterol [35]. Next, we examined whether CA inhibits the activation of SREBPs in osteoclasts. The reporter assay indicated that RANKL increased the transcription activity of SREBPs (Fig. 3a). The mature SREBP2 (mSREBP2) level was increased by RANKL stimulation and was significantly inhibited by CA (Figs. S4A and $3 b$ ). In comparison, RANKL and CA did not induce the mSREBP1 level (Fig. S5A, C). Furthermore, CA significantly inhibited RANKL-induced nuclear localization of SREBP2 (Fig. 3c). Similar results were observed in vivo (Fig. 3d). The expression of the SREBP2 target genes, such as hydroxymethylglutaryl coenzyme A reductase, hydroxymethylglutaryl coenzyme A synthase, low-density lipoprotein receptors, mevalonate kinase, and farnesyl diphosphate synthase, was significantly decreased by CA treatment (Figs. S4B-F and 3e-i). In comparison, the gene expression of SREBP1c was not influenced by CA treatment (Figs. 3j and S4G). These results indicated that CA specifically inhibited SREBP2 activity and may inhibit de novo synthesis of cholesterol and intracellular transport of LDL-c in osteoclasts. Next, we detected the level of TC and TG in osteoclasts formed from either BMMs (Figs. S4H and S5D) or RAW264.7 cells (Figs. 3k and S5A). It was shown that CA significantly decreased TC content in a dosedependent manner (Figs. 3k and $\mathrm{S} 4 \mathrm{H}$ ) but it did not affect cellular TG level (Fig. S5B, D). The effect of CA on cellular TC content was further confirmed by filipin staining (Figs. 31 and S4I). Taken together, these results demonstrated that CA decreased the level of cholesterol by inhibiting SREBP2 activity in RANKL-induced osteoclasts.

\section{CA disrupts the formation of ERRa/PGC1 $\beta$ complex and inhibits the ERRa activity partially depend on reduction of cellular cholesterol in osteoclasts}

In recent studies, it has been shown that the nuclear receptor $\mathrm{ERR} \alpha$ regulates skeletal remodeling by controlling osteoclastogenesis, a key cellular differentiation process essential for bone resorption. Wei et al. demonstrated that cholesterol is an endogenous ligand of $\operatorname{ERR} \alpha$ and promotes osteoclastogenesis by increasing the interaction of $\mathrm{ERR} \alpha$ and PGC1 $\beta$ [31]. As CA suppressed de novo cholesterol biosynthesis and reduced intracellular cholesterol, we reasoned that the interaction between ERR $\alpha / \mathrm{PGC} 1 \beta$ would be weakened. First, we found that CA significantly suppressed RANKL-induced ERR $\alpha$ transactivation in a dose-dependent manner (Fig. 4a), while the transcriptional activity of other members of ERR family including ERR $\beta$, ERR $\gamma$ or Nur77 were not affected (Fig. 4b-d). The interaction between ERR $\alpha$ and PGC1 $\beta$ was largely disrupted after CA treatment (Fig. 4e, f). RANKL stimulated the expression of ERR $\alpha$ target genes that promote mitochondrial and osteoclast activity, such as Aconitate hydratase 2, Isocitrate Dehydrogenase 3 (NAD (+)) alpha $(I D H 3 \alpha)$, Acp 5, Short-chain specific acyl-CoA dehydrogenase $(S C A D)$, Medium-chain specific acyl-CoA dehydrogenase $(M C A D)$, ATP synthase subunit beta (ATP5b), and $N d g 2$ (Figs. S6A-F and $4 \mathrm{~g}-\mathrm{m}$ ). $\mathrm{CA}$ significantly decreased these $\mathrm{ERR} \alpha$ target genes expression (Figs. S6A-F and $4 \mathrm{~g}-\mathrm{m}$ ). These results demonstrated that CA significantly disrupted the RANKLinduced activity of ERR $\alpha$.

Surprisingly, when exogenous cholesterol was added to CA-treated cells, the inhibition of $\operatorname{ERR} \alpha$ activity was only partially reversed (Fig. 5a), although the ERR $\alpha$ and PGC1 $\beta$ binding were completely recovered (Fig. 5b). Consistently, there was only a partial reversal of the suppressed ERR $\alpha$ target gene expression (Fig. 5c-j). Similarly, the inhibition effect of osteoclasts formation by CA was also partially mitigated in cholesterol replenishment experiment (Fig. 5k-1). In addition, exogenous overexpression of mSREBP2 reproduced the cholesterol replenishment experiment (Fig. S7A-D). These results indicated that CA suppressed osteoclastogenesis only partially depending on reducing the cholesterol content and $\mathrm{ERR} \alpha / \mathrm{PGC} 1 \beta$ complex formation.

\section{CA promotes the ubiquitination-proteasomal degradation of ERRa}

Next, we found that CA significantly decreased the protein level of ERR $\alpha$ (Figs. 6a and S8A) without affecting its 
A

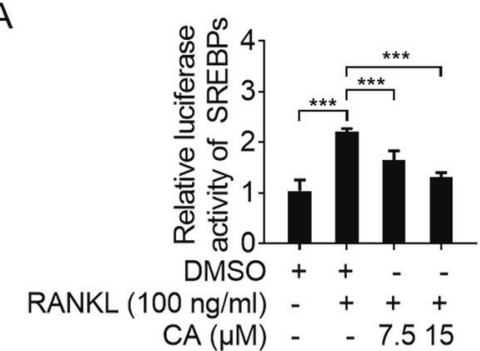

C
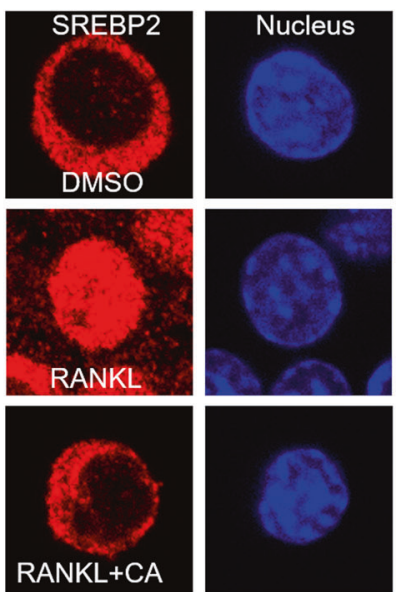

D ovX

OVX+E2 (0.1 mg/kg)
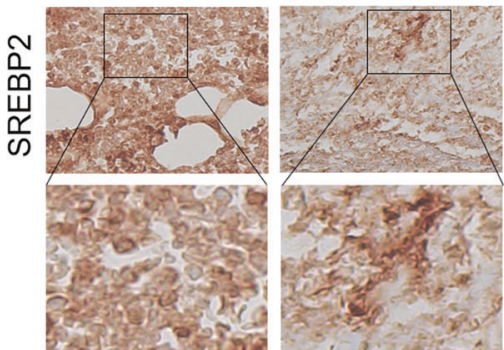

$\mathrm{OVX}+\mathrm{CA}(30 \mathrm{mg} / \mathrm{kg})$
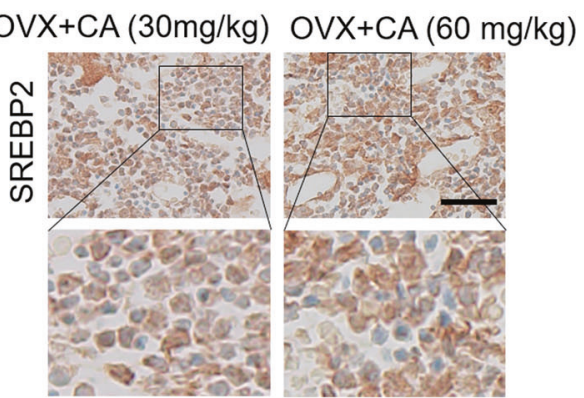

Fig. 3 CA decreases the level of cholesterol by inhibiting SREBP2 activity in RANKL-induced osteoclasts. a The SRE luciferase reporter plasmid was co-transfected into the RAW264.7 cells with expression plasmid for $\beta$-gal for $24 \mathrm{~h}$. The cells then were incubated with or without the indicated concentrations of CA and stimulated with $100 \mathrm{ng} / \mathrm{ml}$ of RANKL for another $24 \mathrm{~h}$. Cell supernatants were collected and assayed for luciferase activity. b-c RAW264.7 cells were incubated with or without $100 \mathrm{ng} / \mathrm{ml} \mathrm{RANKL}$, followed by treatment with indicated concentration of CA for $48 \mathrm{~h}$. b The cells were lysed and the mature SREBP2 were detected by western blot (WB) (left) and
E

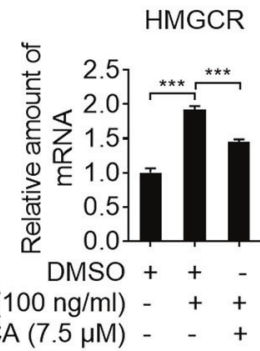

G

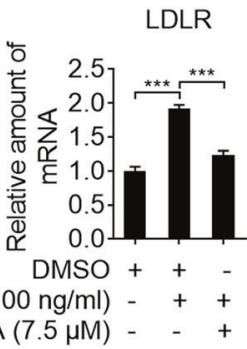

।

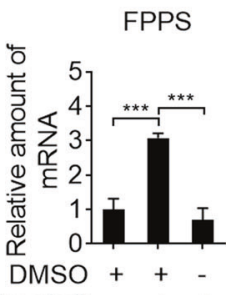

RANKL $(100 \mathrm{ng} / \mathrm{ml})-++$ $\mathrm{CA}(7.5 \mu \mathrm{M})-\cdots$

$\mathrm{K}$

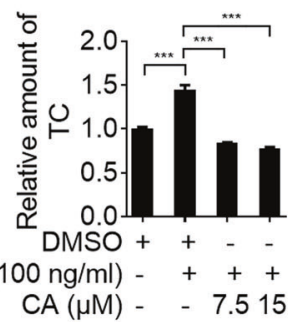

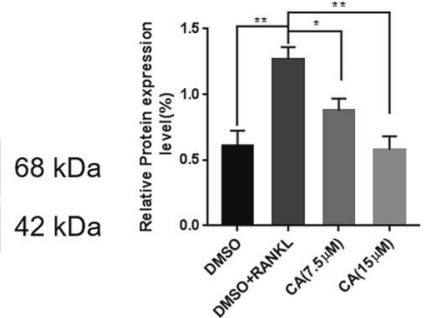

$\mathrm{F}$

HMGCS

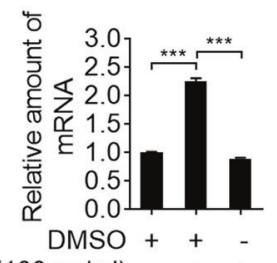

RANKL $(100 \mathrm{ng} / \mathrm{ml})-++$

$\mathrm{CA}(7.5 \mu \mathrm{M})-\quad-+$

$\mathrm{H}$

RANKL (100 ng/ml) - + +

$\mathrm{CA}(7.5 \mu \mathrm{M})-\quad-+$

$J$

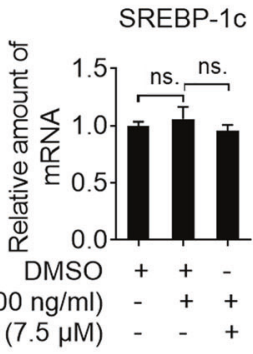

L

Filipin staining

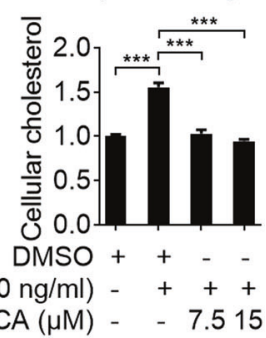

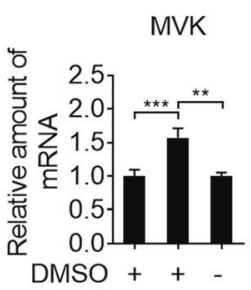

quantification of normalized mature SREBP2 levels to actin controls (right). c The localization of SREBP2 in cells was visualized by immunofluorescence. d The localization of SREBP2 in osteoclast of treated mice by immunochemistry. $\mathbf{e}-\mathbf{j}$ RT-qPCR was used to assess relative mRNA expression levels of indicated genes. k-l RAW264.7 cells were incubated with or without $100 \mathrm{ng} / \mathrm{ml}$ RANKL, followed by treatment with indicated concentration of CA for 5 days. $\mathbf{k}$ The cellular TC was detected by the detection kit. 1 Cholesterol was stained by Filipin. All experiments were repeated three times. Bars represent means \pm SD. $* p<0.05, * * p<0.01, * * * p<0.005$. 
A

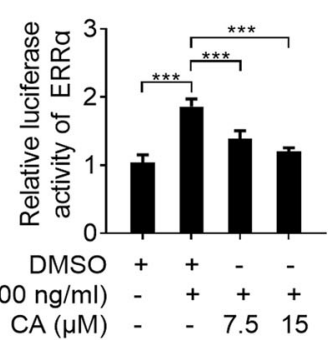

D

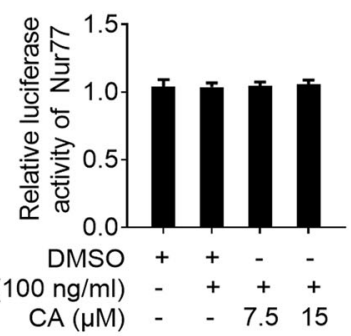

G

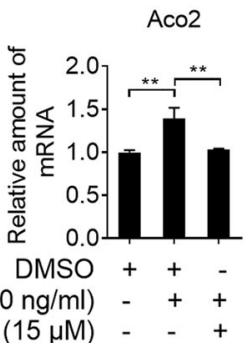

$\mathrm{K}$

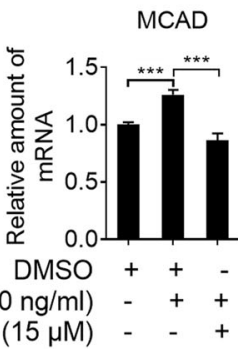

B

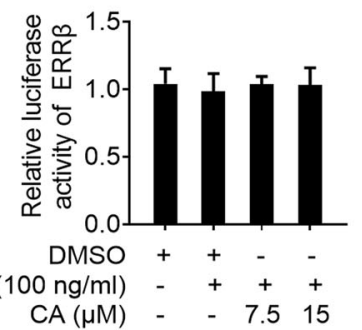

E

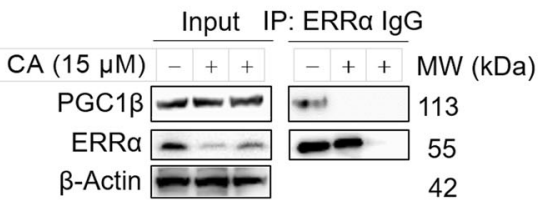

C
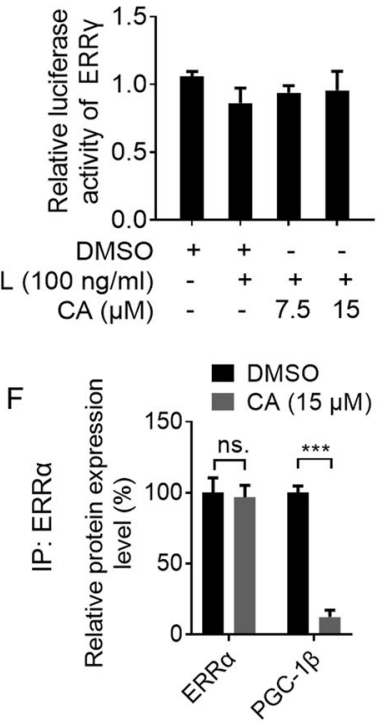

$\mathrm{IDH} 3 \alpha$

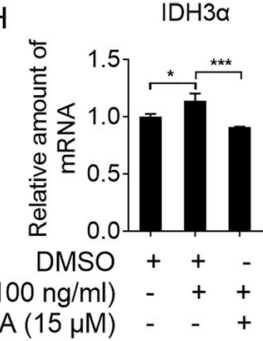

$\mathrm{L}$

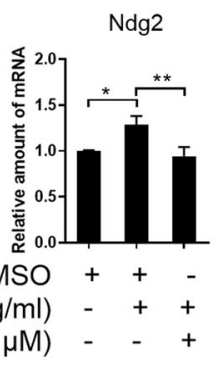

Fig. 4 CA inhibits the ERR $\alpha$ activity in RANKL-induced osteoclasts. a-d The indicated luciferase reporter plasmid was cotransfected into the RAW264.7 cells with expression plasmid for $\beta$-gal for $24 \mathrm{~h}$. The cells then were incubated with or without the indicated concentrations of CA and stimulated with $100 \mathrm{ng} / \mathrm{ml}$ of RANKL for another $24 \mathrm{~h}$. Cell supernatants were collected and assayed for luciferase activity. e Co-immunoprecipitation analysis of the effects of CA on ERR $\alpha$ and PGC1 $\beta$ interaction. RAW264.7 cells

mRNA expression (Figs. 6b and S8B). This effect was comparable with XCT790, an inverse antagonist of ERR $\alpha$ [36]. Consistently, the protein level of ERR $\alpha$ was also obviously decreased in CA-treated OVX mice (Fig. 6c). Although XCT790 obviously promotes ERR $\alpha$ degradation, it significantly exhibited cytotoxicity at $20 \mu \mathrm{M}$ concentration (Fig. S9A). Moreover, XCT790 greatly increased mSREBP2 proteins (Fig. S9B), subsequently increases expression of SREBP2 target genes (Fig. S9C-H). As CA

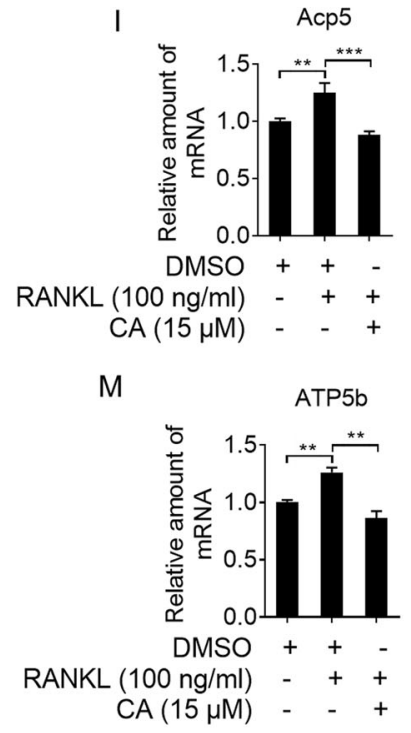

were treated with $100 \mathrm{ng} / \mathrm{ml}$ RANKL for 5 days in the presence of $15 \mu \mathrm{M}$ CA. f Quantification of indicated protein levels of Fig. 5e. g-m RAW264.7 cells were incubated with or without $100 \mathrm{ng} / \mathrm{ml}$ RANKL, followed by treatment with indicated concentration of CA for 5 days. RT-qPCR was used to assess relative mRNA expression levels of indicated genes. All experiments were repeated three times. Bars represent means \pm SD. $* p<0.05, * * p<0.01, * * * p<0.005$.

reduced both SREBP2 and ERR $\alpha$ protein levels without causing cytotoxicity, CA has certain therapeutic advantages compared with XCT790. As shown in Fig. 6d, the reduction of ERR $\alpha$ was caused by the increased turnover of ERR $\alpha$. CA substantially increased the ubiquitination of ERR $\alpha$ (Fig. 6f). MG-132, a proteasome inhibitor, abolished the effect of ERR $\alpha$ depletion by CA (Fig. 6e). These results indicated that CA promoted ERR $\alpha$ proteasomal degradation. 
A

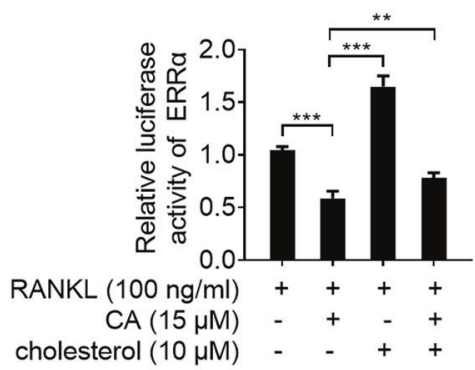

C

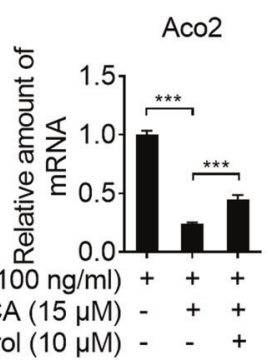

$\mathrm{G}$

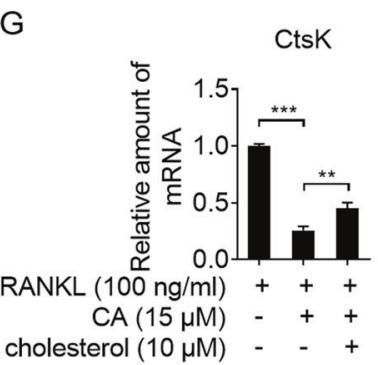

B

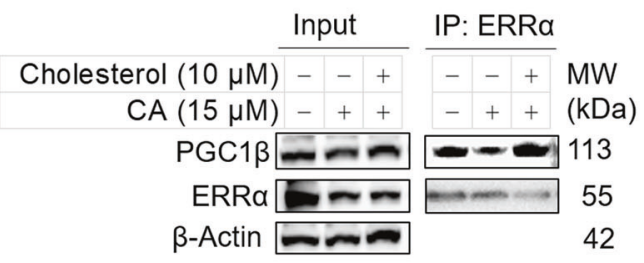

IP: ERRa

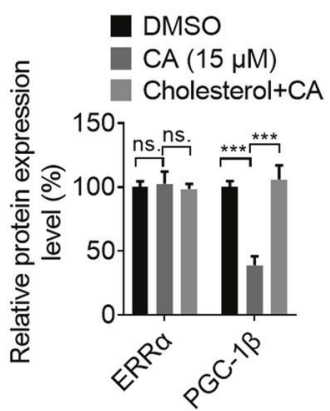

D

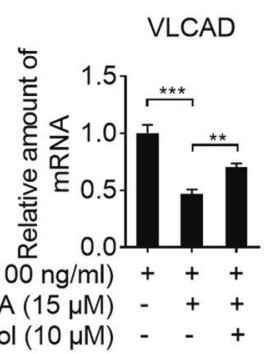

$\mathrm{H}$

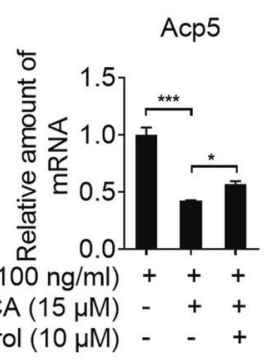

\begin{abstract}
$E$
\end{abstract}

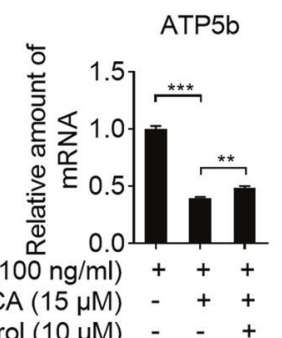

RANKL $(100 \mathrm{ng} / \mathrm{ml})+++$ cholesterol $(10 \mu \mathrm{M})--+$

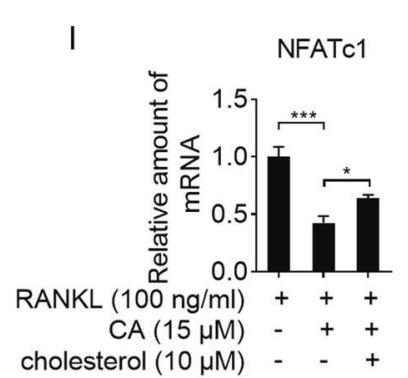

$\mathrm{F}$

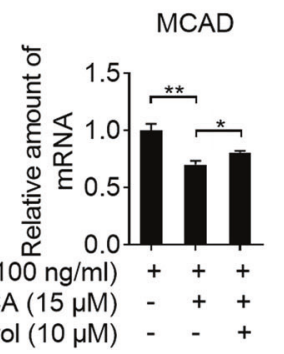

$\begin{array}{r}\text { RANKL }(100 \mathrm{ng} / \mathrm{ml})++\quad+ \\ \text { CA }(15 \mu \mathrm{M})-++ \\ \text { cholesterol }(10 \mu \mathrm{M})-+ \\ \hline\end{array}$

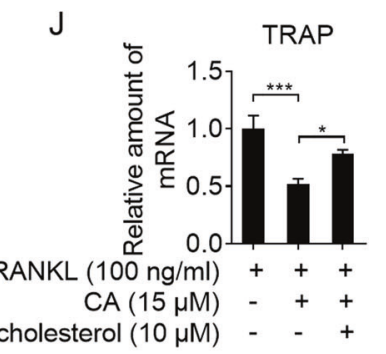

$\mathrm{K}$
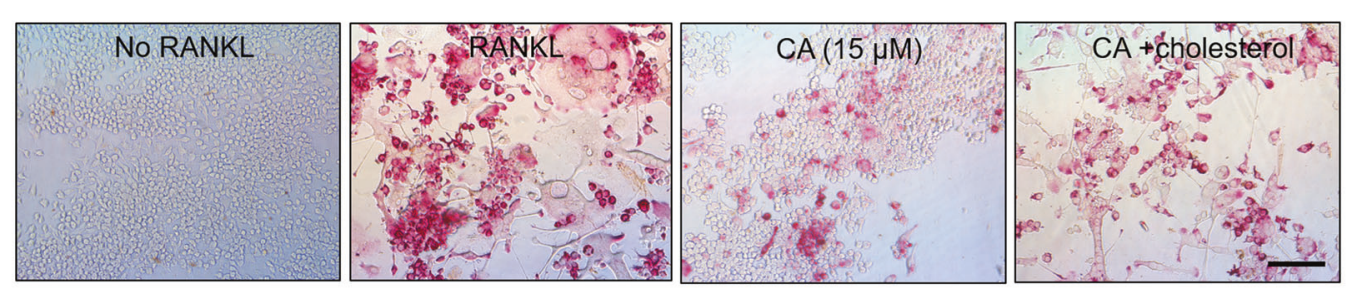

L

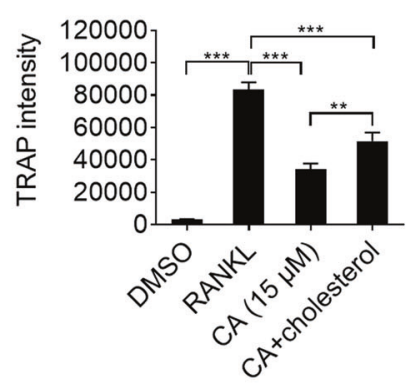

Fig. 5 Cholesterol partially reverses the inhibition of ERR $\alpha$ activity and osteoclastogenesis by CA treatment. a The ERR $\alpha$ luciferase reporter plasmid was transfected into the RAW264.7 cells with expression plasmid for $\beta$-gal for $24 \mathrm{~h}$. Cells then were incubated with or without $15 \mu \mathrm{M} \mathrm{CA}$ or $10 \mu \mathrm{M}$ cholesterol and stimulated with $100 \mathrm{ng} / \mathrm{ml}$ of RANKL for another $24 \mathrm{~h}$. Cell supernatants were collected and assayed for luciferase activity. b-j RAW264.7 cells were treated with $100 \mathrm{ng} / \mathrm{ml}$ RANKL for 5 days in the presence of $15 \mu \mathrm{M}$
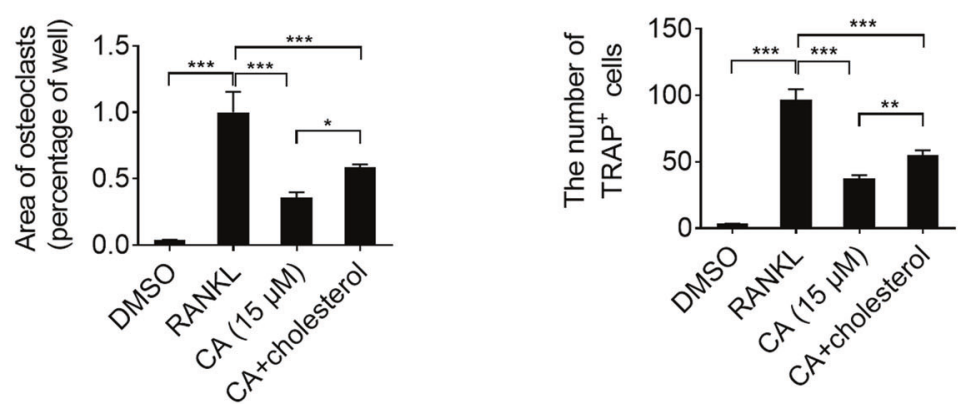

CA or $10 \mu \mathrm{M}$ cholesterol. b The cells were lysed and the proteins were detected by WB (left), quantification of indicated protein levels (right). $\mathbf{c}-\mathbf{j}$ RT-qPCR was used to assess relative mRNA expression levels of indicated genes. $\mathbf{k}$ TRAP-positive osteoclast treated with $15 \mu \mathrm{M}$ CA or $10 \mu \mathrm{M}$ cholesterol followed by stimulation with $100 \mathrm{ng} / \mathrm{ml}$ RANKL for 5 days. I Quantification of area of osteoclasts, TRAP-positive multinuclear cells and TRAP intensity. All experiments were repeated three times. Bars represent means \pm SD. ${ }^{*} p<0.05,{ }^{* *} p<0.01,{ }^{* * *} p<0.005$. 
A

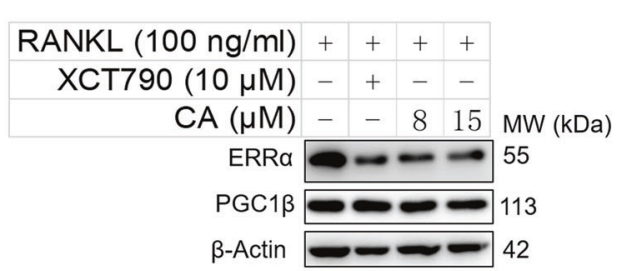

C

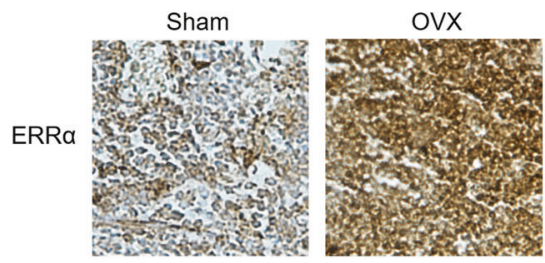

D

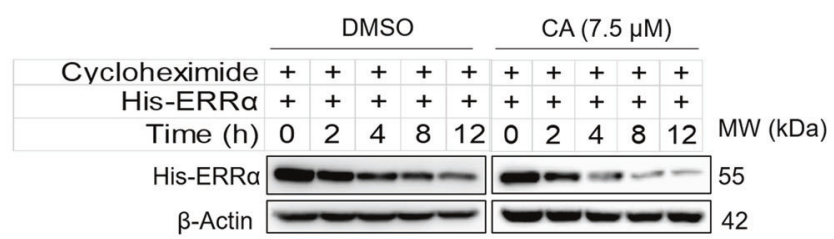

B

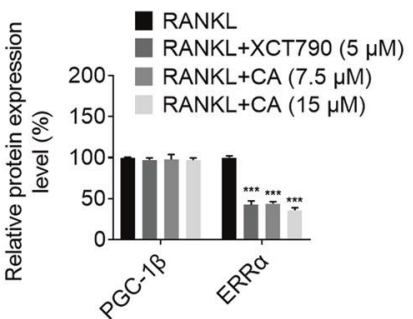

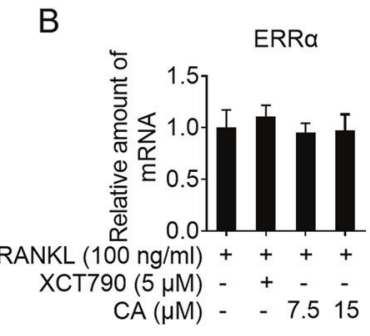
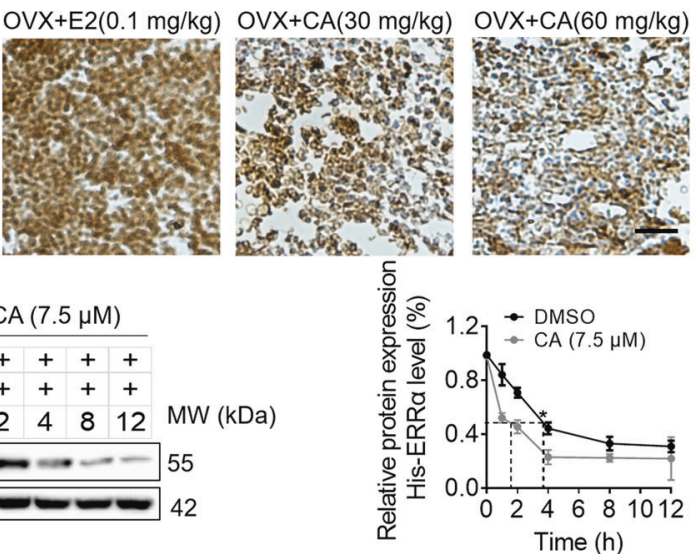

$E$

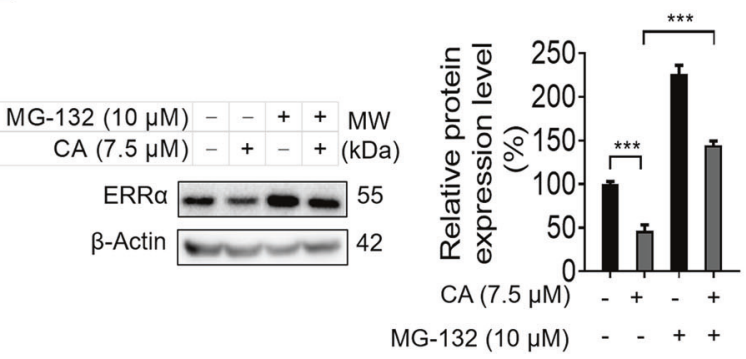

$\mathrm{F}$

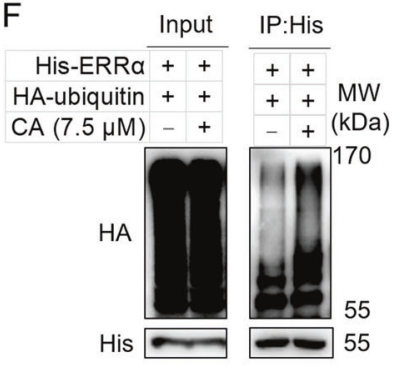

HA-ubiquitin

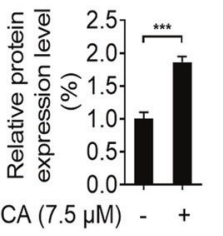

Fig. 6 CA promotes the ubiquitination proteasome degradation of ERRo. RAW264.7 cells were treated with $100 \mathrm{ng} / \mathrm{ml}$ RANKL for 5 days in the presence of CA $(7.5,15 \mu \mathrm{M})$ or XCT790 $(10 \mu \mathrm{M})$. a The cells were lysed and the proteins were detected by WB (left), quantification of indicated protein levels (right). b RT-qPCR was used to assess relative mRNA expression levels of ERR $\alpha$ genes. $\mathbf{c}$ The protein level of ERR $\alpha$ in mice was detected by immunohischemistry. d $293 \mathrm{~T}$ cells were transfected with His-ERR $\alpha$ plasmid for $24 \mathrm{~h}$, and then incubated with $100 \mu \mathrm{M}$ cycloheximide for $1 \mathrm{~h}$, afterwards, the cells were supplemented with $50 \mu \mathrm{M}$ cycloheximide plus vehicle, or $7.5 \mu \mathrm{M}$ CA for indicated time. His-ERR $\alpha$ was detected by WB (left),

\section{STUB1 is identified as the E3 ligase of ERRa and mediates its ubiquitylation and proteasomal degradation}

To identify the E3 ligase (E3s) of ERR $\alpha$, we employed UbiBrowser25, an integrated bioinformatics platform to predict the proteome-wide E3-substrate network based on naive Bayesian network (http://ubibrowser.ncpsb.org). We queried ERR $\alpha$ as substrate, 108 predicted E3 ligases in UbiBrowser are presented in Fig. 7a. These E3s were classified into different families and shown in the E3 family quantification of His-ERR $\alpha$ protein levels (right). e RAW264.7 cells were treated with $100 \mathrm{ng} / \mathrm{ml}$ RANKL for 5 days in the presence of CA $(7.5 \mu \mathrm{M})$ or MG-132 $(10 \mu \mathrm{M})$. The cells were lysed and the proteins were detected by WB (left), quantification of indicated protein levels (right). f 293T cells were transfected with His-ERR $\alpha$ and HA-ubiquitin plasmids for $24 \mathrm{~h}$, the cells then were supplemented with or without $7.5 \mu \mathrm{M}$ CA for another $24 \mathrm{~h}$, the cells were lysed and proteins were detected by WB (left), quantification of indicated protein levels (right). All experiments were repeated three times. Bars represent means \pm SD. $* p<0.05, * * p<0.01, * * * p<0.005$.

hierarchical tree (Fig. 7a, right panel). Five E3 ligases with top confidence scores among 108 predicted E3s were filtered and listed (Fig. 7b). To further confirm the E3 ligase of ERR $\alpha$, we separately overexpressed these five E3s (NEDD4, BARD1, MDM2, STUB1, and SMUPF1) and examined the ERR $\alpha$ level accordingly. Only MDM2 and STUB1 overexpression led to decreased ERR $\alpha$ protein level (Fig. 7c). Further, we assessed protein level of ERR $\alpha$ in cells transfected with either MDM2 or STUB1 siRNAs. STUB1 knockdown significantly increased the ERR $\alpha$ protein level (Fig. 7d), while MDM2 knockdown did not affect 
A

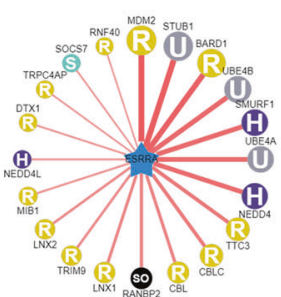

E3 hierarchical tree 0

$\Delta \cup$ COMPLEX(number=16) (E) F-box(number=2)

(2) $\mathrm{V}$ BTB_3(number $=2$ )

D. DWD(number=9)

S) SocS_VHL_BC-box(number $=2$ )

10 SINGLE(number=88)

๑) SINGLE_OTHER(number=10)

Ü UBOX(number=6)

(H) HECT (number $=24$

GECT(number $=24$
C

\begin{tabular}{|c|c|c|c|c|c|c|c|}
\hline His-ERRa & - & + & + & + & + & & \\
\hline lag-NEDD4 & & - & + & - & - & & - \\
\hline ag-BARD1 & - & 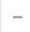 & - & + & - & & - \\
\hline $\mathrm{g}-\mathrm{N}$ & - & - & - & - & + & - & - \\
\hline م & 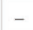 & 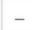 & 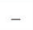 & - & - & + & \\
\hline
\end{tabular}

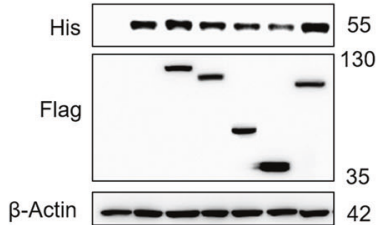

His-ERRa -++++++

Flag-NEDD4

Flag-BARD1

Flag-MDM2

Flag-STUB1

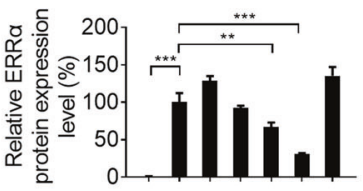

D

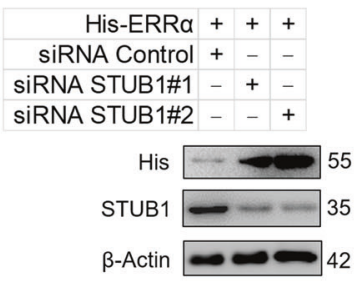

His-ERRa + + +

siRNA Control + SIRNA STUB1\#1 SIRNA STUB1\#2

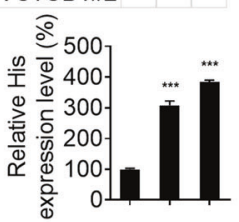

E

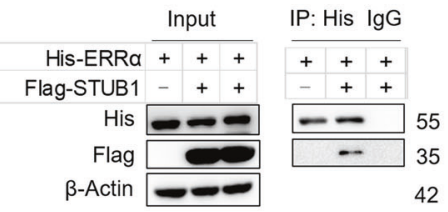

G

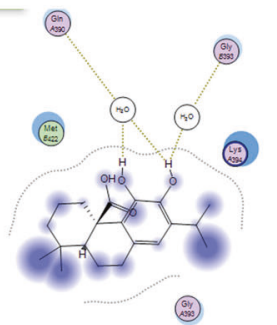

$\mathrm{F}$

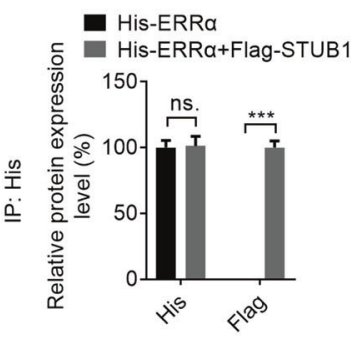

$\mathrm{H}$

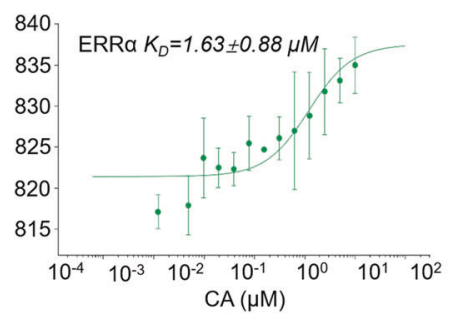

siRNA Control + + siRNA STUB1\#1 siRNA STUB1\#2

His-ERRa + + + +

$\mathrm{CA}(15 \mu \mathrm{M})-+++$

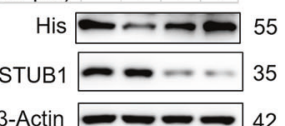

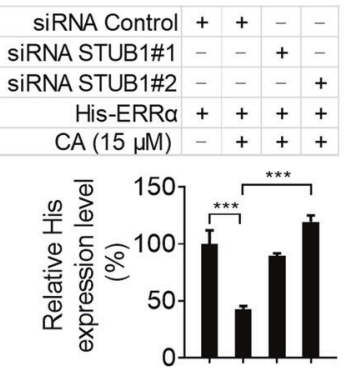

I

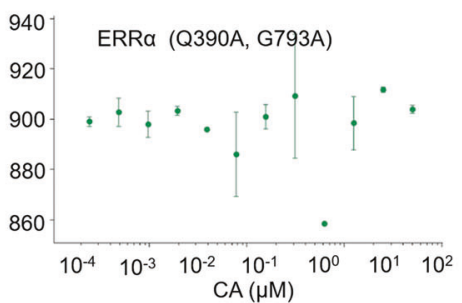

J

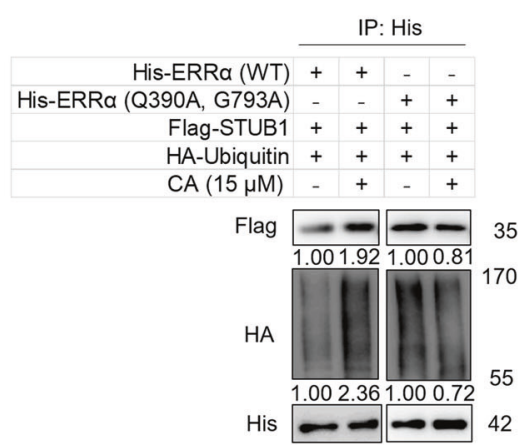

K

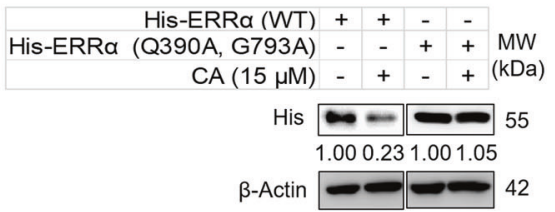

ERR $\alpha$ protein level (Fig. S10). These data suggest that only STUB1 is sufficient and required for ERR $\alpha$ degradation. We then validated the interaction between ERR $\alpha$ and its potent E3 ligase (STUB1). STUB1 was co-immunoprecipitated with ERR $\alpha$ (Fig. 7e). Taken together, these data suggested that STUB1 as a bona fide E3 ligase of 
Fig. 7 STUB1 is identified as E3 ligase of ERR $\alpha$ and mediated the ERR $\alpha$ degradation by CA treatment. a A network view of E3$\mathrm{ERR} \alpha$ interactions (left panel) and the E3 hierarchical tree for ERR $\alpha$ (right panel). UbiBrowser was employed to explore the E3 ligases for ERR $\alpha$. The representative predicted E3 ligases surround ERR $\alpha$. The node colors and characters reflect the E3 type. The edge width, the node size, and the edge shade are corrected with the confidence score. The predicted E3s and their position in the E3 family hierarchical tree was presented. In this tree, texts in each circle (just like "U," "R," and " $\mathrm{H}$ ") represent the E3 family. The number in the bracket following each E3 family represents the number of corresponding predicted E3ERR $\alpha$ interaction. $\mathbf{b}$ The information of top five confidence of ERR $\alpha$ E3 ligases. c 293T cells were transfected with indicated plasmids for $24 \mathrm{~h}$. Cells were then lysed and the proteins were detected by WB (left), quantification of His-ERR $\alpha$ protein levels (right). d 293T cells were transfected with indicated siRNAs for $72 \mathrm{~h}$. Cells were then lysed and the proteins were detected by WB (left), quantification of HisERR $\alpha$ protein levels (right). e The interaction of ERR $\alpha$ with STUB1 was detected by co-immunoprecipitation. f 293T cells were transfected with indicated siRNAs and His-ERR $\alpha$ plasmids for $72 \mathrm{~h}$. The cells then treated with CA for $24 \mathrm{~h}$. Cells then lysed and the proteins were detected by WB (left), quantification of His-ERR $\alpha$ protein levels (right). $\mathbf{g}$ Molecular docking of CA to ERR $\alpha$. h The interaction between ERR $\alpha$ and CA was detected by MST. i The interaction between a mutant (Q390A, G793A) form of ERR $\alpha$ and CA was detected by MST. j 293T cells were transfected with indicated plasmids for $24 \mathrm{~h}$. Cells were then treated with CA for another $24 \mathrm{~h}$. the cells then lysed and the interaction of ERR $\alpha$ with STUB1 and Ubiquitin was detected by co-immunoprecipitation. k 293T cells were transfected with indicated plasmids for $24 \mathrm{~h}$. the cells then treated with $\mathrm{CA}$ for another $24 \mathrm{~h}$. the cells then lysed and the proteins were detected by WB. All experiments were repeated three times. Bars represent means \pm SD. $* p<0.05, * * p<0.01, * * * p<0.005$.

ERR $\alpha$. Consistently, in STUB1 knockdown cells, CA no longer reduced ERR $\alpha$ protein level (Fig. 7f), suggesting CA promotes ERR $\alpha$ proteasomal degradation via STUB1 mediated ubiquitination.

\section{CA binds directly to ERRa and promotes its proteasomal degradation}

Based on the above results, we reasoned that CA might be an ERR $\alpha$ inverse agonist that reduces the stability of ERR $\alpha$. In order to verify this conjecture, we first assessed whether $\mathrm{CA}$ binds to ERR $\alpha$ through a virtual docking assay. The results showed that the binding energy between ERR $\alpha$ and $\mathrm{CA}$ is $-11.27 \mathrm{~kJ} / \mathrm{mol}$. More specifically, two hydrogen bonds are formed between the two phenolic hydroxyl groups of CA and Gln390 and Gly393 in the ligand-binding domain of ERR $\alpha$ (Fig. 7g). Afterwards, a direct binding between CA and ERR $\alpha$ was detected by the MST assay, the result showed that the $K_{D}$ between CA and ERR $\alpha$ was 1.63 $\pm 0.88 \mu \mathrm{M}$ (Fig. $7 \mathrm{~h}$ ). After the residues Gln390 and Gly393 of ERR $\alpha$ were mutated to alanine (Q390A, G793A) to prevent hydrogen bond formation, the binding between CA and the mutated ERR $\alpha$ protein got lost (Fig.7i). CA increased the binding ERR $\alpha$ and STUB1, and increased the ubiquitination of ERR $\alpha$ (Fig. 7j). CA neither increased the interaction of mutated ERR $\alpha$ (Q390A, G793A) with STUB1 nor upregulated the ubiquitination of mutated ERR $\alpha$ (Q390A, G793A) (Fig. 7j). Consequently, CA did not lead to the mutated ERR $\alpha$ (Q390A, G793A) degradation (Fig. 7k). In conclusion, these results suggest that CA directly binds to ERR $\alpha$, promoting its interaction with its $\mathrm{E} 3$ ligase STUB1. Then ERR $\alpha$ undergoes ubiquitination and proteasomal degradation.

\section{CA promotes STUB1 mediated ERRa ubiquitination at $\mathrm{K} 51$ and $\mathrm{K} 68$}

We then used the UbPred database (http://www.ubpred.org) to predict the ubiquitination site of ERR $\alpha$. As shown in Fig. S11A, B, six lysine residues were predicted to be ERR $\alpha$ ubiquitination sites. When all six lysine residues were mutated to alanines, the mutated ERR $\alpha$ (6KA) were resistant to CA-mediated proteasomal degradation (Fig. 8a). We further mutated each of these six lysines to alanines. It turned out that K51A and K68A mutations got resistance against CA induced proteasomal degradation (Fig. 8b). Thus, the ubiquitination sites of ERR $\alpha$ were successfully identified. In conclusion, CA bound to ERR $\alpha$, leading to STUB1 mediated ubiquitination at K51 and K68, causing ERR $\alpha$ proteosomal degradation. Next, we co-transfected PGC1 $\beta$ and ERR $\alpha$ wild type or mutant (6KA) overexpression plasmids in RAW264.7 cells. The ERR $\alpha$ target genes suppressed by CA were reversed (Fig. 8c, d) by mutant ERR $\alpha$ (6KA), but not wild-type ERR $\alpha$, consistent with results in Fig. 8a. Meanwhile, the inhibition effect of osteoclasts formation by CA was also obviously reversed in cells overexpressed ERR $\alpha$ (6KA), but not wild-type ERR $\alpha$ (Fig. 8e, f). These data suggest that ERR $\alpha$ degradation is essential for CA efficacy in inhibiting osteoclasts differentiation.

\section{Discussion}

Bone maintenance depends on a balance between bone formation and bone resorption that implicates osteoblasts and osteoclasts and the osteocytes that modulate response of bone mechanical stress [37, 38]. Many studies have identified a link between dyslipidemia and low BMD for postmenopausal women [39]. Interestingly, osteoporosis is mainly due to an excess of osteoclasts since the amount of bone resorbed by the osteoclasts is not restored with the new bone deposited by the osteoblasts, suggesting that cholesterol may directly act through osteoclasts to induce bone loss in postmenopausal women [40]. Recently, cholesterol was shown to be the exogenous ligands of ERR $\alpha$, and has the ability to recruit coactivators PGC1 $\beta$ to ERR $\alpha$ in osteoclasts. ERR $\alpha$ mediated the effect of cholesterol on 
A

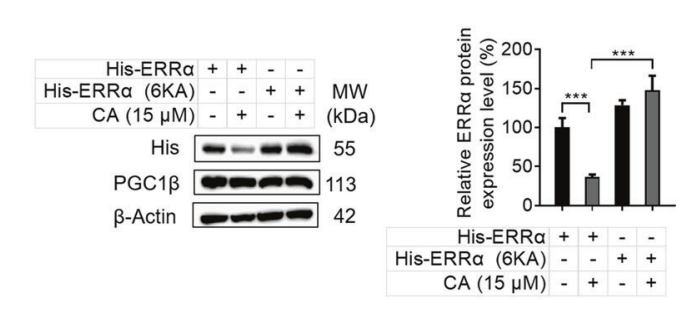

B

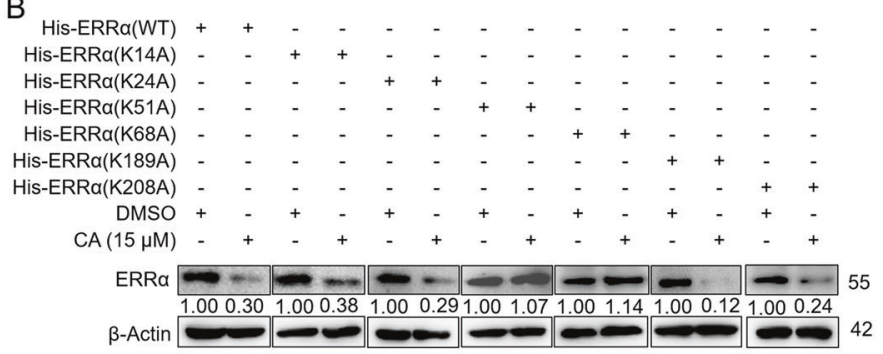

C

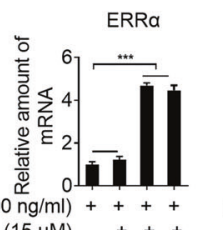

$\operatorname{RANKL}(100 \mathrm{ng} / \mathrm{ml})++++$
CA $(15 \mu \mathrm{M})-+++$ His-ERRa (6KA) - - +

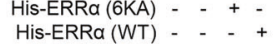

RANKL

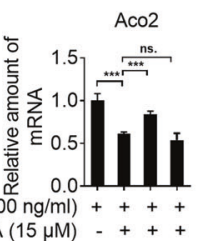

$\mathrm{CA}(15 \mu \mathrm{M})++++$

His-ERRa (6KA) - - +

His-ERRa (WT) - - + +

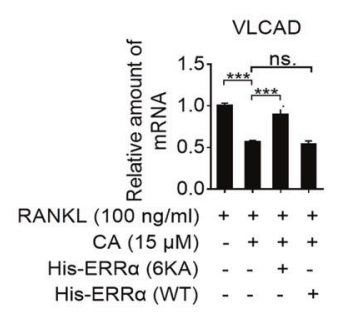

D

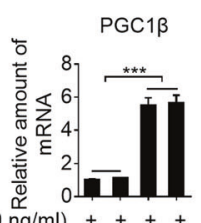

RANKL $\left(100 \frac{\mathscr{\gamma}}{\mathrm{ng} / \mathrm{ml}}\right)++++$ $\mathrm{CA}(15 \mu \mathrm{M})-+++$ His-ERRa (6KA) - - + His-ERRa (WT) - - - +

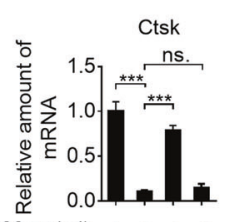

RANKL $(100 \mathrm{ng} / \mathrm{ml})++++$
CA $(15 \mu \mathrm{M})-+++$ $\mathrm{CA}(15 \mu \mathrm{M})$
$-\quad+++$

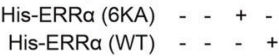

E
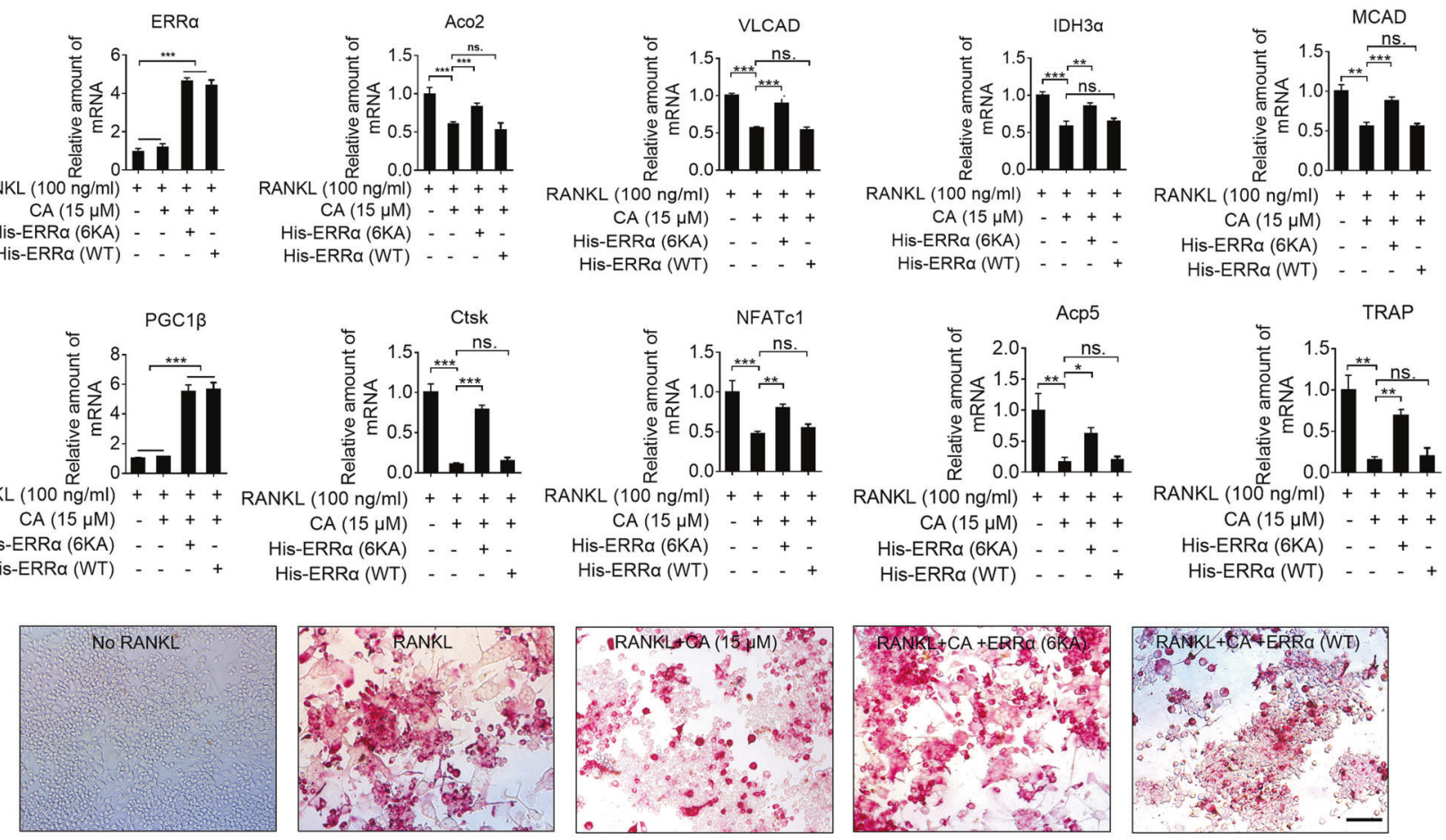

F
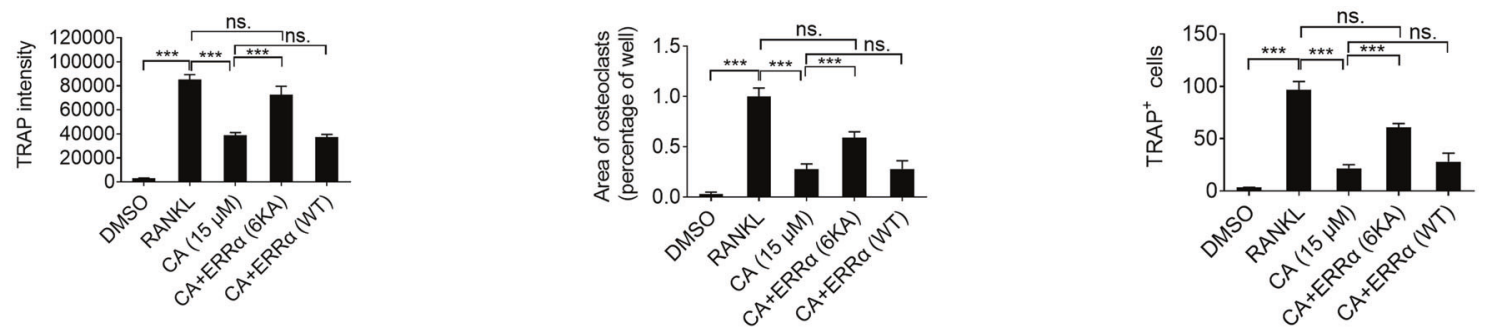

Fig. 8 CA mediated ERRo ubiquitination at $\mathrm{K51}$ and $\mathrm{K68}$ is essential for inhibiting osteoclast differentiation. a $293 \mathrm{~T}$ cells were transfected with indicated plasmids for $24 \mathrm{~h}$. The cells then treated with CA for $24 \mathrm{~h}$, the cells then lysed and the proteins were detected by WB (left), quantification of His-ERR $\alpha$ protein levels (right). b 293T cells were transfected with indicated ERR $\alpha$ mutation plasmids for $24 \mathrm{~h}$, the cells then treated with CA for $24 \mathrm{~h}$, the cells then lysed and the proteins were detected by WB. c-e The wild-type ERR $\alpha$ and mutated ERR $\alpha$ (6KA) plasmids were co-transfected with PGC1 $\beta$ into

bone resorption and skeletal remodeling [31]. Therefore, inhibition of intracellular cholesterol level may be a strategy to inhibit the osteoclasts formation. In previous studies, it has been demonstrated that SREBP2 is associated to osteoclast differentiation and SREBP2 inhibitors, such as the RAW264.7 cells for $24 \mathrm{~h}$, the cells then were incubated with or without CA and stimulated with $100 \mathrm{ng} / \mathrm{ml}$ of RANKL for another 5 days. c-d qRT-PCR was used to assess relative mRNA expression levels of indicated ERR $\alpha$ target genes. e TRAP-positive osteoclasts were stained by kit. f Quantification of area of osteoclasts, TRAPpositive multinuclear cells and TRAP intensity. All experiments were repeated three times. Bars represent means \pm SD. ${ }^{*} p<0.05$, $* * p<$ $0.01, * * * p<0.005$.

fatostatin and anhydroicaritin inhibit osteoclast formation [21-23]. However, the physiological functions of SREBP2 in osteoclast remain unclear. Here, we reported that RANKL activates SREBP2 transcription activity, increases the content of cholesterol, which is the endogenous agonist 


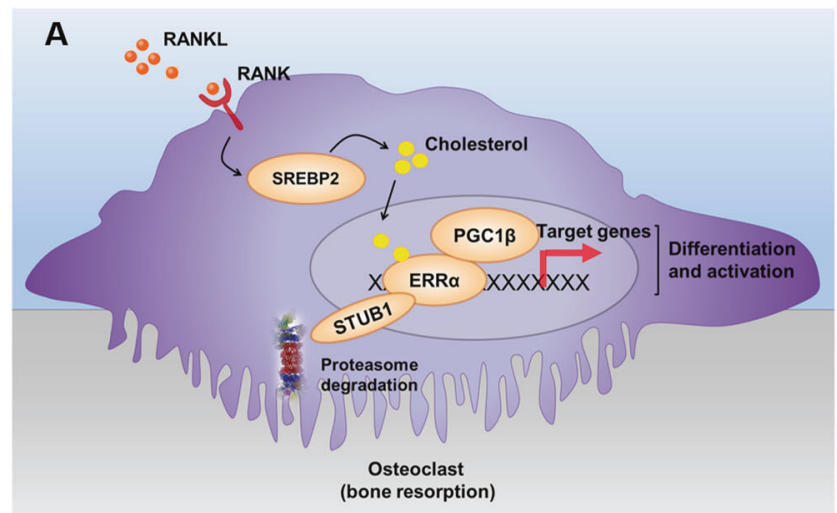

Fig. 9 Schematic diagram of CA. a Binding of RANKL to its cognate receptor RANK leads to activation of SREBP2 and de novo cholesterol synthesis. Cholesterol promotes ERR $\alpha$ and PGC1 $\beta$ binding and increases osteoclastogenesis gene expression. b CA prevents

of ERR $\alpha$, therefore, accelerates osteoclasts formation. CA, a potent inhibitor of SREBP2, reduced the ERR $\alpha$ activity and inhibits osteoclasts formation through decreasing the level of cholesterol.

In view of the important role in the pathogenesis of osteoporosis, SREBP2, and ERR $\alpha$ have been considered as therapeutic targets for the treatment of osteoporosis. In this study, for the first time, we found CA as a dual-targeted drug against SREBP2 and ERR $\alpha$ with a potent effect to treat osteoporosis. Although SREBP2 and ERR $\alpha$ also have a correlation with the regulation of osteoblasts, CA has no significant effect on osteoblast formation. Moreover, there was no significant effect on SREBP1c expression and fatty acid metabolism in osteoclasts. These data show that CA has a good specific inhibitory effect of cholesterol metabolism.

Currently, the drugs for clinical treatment of osteoporosis are mainly divided into basic supplements, bone resorption inhibitors, and bone formation accelerating agents. Hormone replacement therapies (HRT) preserve BMD and prevent fractures during menopause [41]. However, estrogen exposure is suspected to have an association with increased risk of breast cancer, endometrial cancer, and cervical cancer [42-44]. Therefore, safer treatment regimens are needed for postmenopausal women with osteoporosis. Cholesterol promotes breast tumor growth and metastasis in murine models [45, 46]. SREBP2, the major transcription factor that control cholesterol biosynthesis, was found to be highly expressed in breast cancer tissues and correlated with a poor prognosis. SREBP2 was similarly under the transcriptional control of CREB and its induction regulates the expression of matrix metalloproteinases, key degradative enzymes involved in bone metastases by breast cancer cells. Accordingly, targeting of SREBP2 with fatostatin attenuated breast cancer-induced osteolysis in vivo [24]. Meanwhile, ERR $\alpha$ was reported to

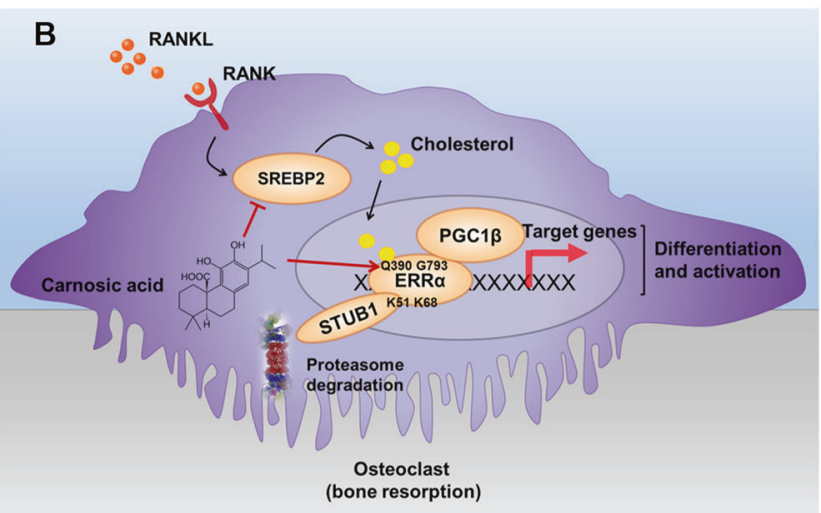

SREBP2 nucleus translocation and reduced cholesterol level in osteoclasts. Meanwhile, CA binds to ERR $\alpha$ and leads to K51 and K68 ubiquitination via STUB1. ERR $\alpha$ then undergoes proteosomal degradation and osteoclastogenesis gene expression is suppressed.

be a potent diagnostic and prognostic factor in human breast carcinoma $[47,48]$. The overexpression of ERR $\alpha$ stimulates VEGF expression in primary tumors, promoting angiogenesis [49]. ERR $\alpha$ also supports breast cancer bone metastasis by increasing RANK expression [50]. In conclusion, SREBP2 and ERR $\alpha$ are considered to be important targets for the treatment of breast cancer. In our study, CA exerted both SREBP2 and ERR $\alpha$ inhibitory effects, thus leading to suppress breast cancer and cervical cancer progression (Fig. S12A-F). Taken together, our strategy by dual targeting of SREBP2 and ERR $\alpha$ has significant security advantages over traditional HRT. Therefore, inhibition of SREBP2 and ERR $\alpha$ may become a new generation of therapeutic strategy for osteoporosis in menopausal women.

PROteolysis-TArgeting Chimeras (PROTACs) technology has been used for eliminating "undruggable" proteome for targeted therapies [51, 52]. ERR $\alpha$ has receiving much attention in developing PROTACs molecules [53, 54]. These compounds are all designed via von Hippel-Lindau protein-based ubiquitination and proteasomal degradation [55]. The ERR $\alpha$ E3 ligases, as well as its ubiquitination sites, are yet to be clarified. In this study, we found that CApromoted ERR $\alpha$ ubiquitination and proteasomal degradation by directly interacting with ERR $\alpha$. STUB1 was discovered to regulate $\mathrm{ERR} \alpha$ protein stability in osteoclasts. After CA binds to ERR $\alpha$, STUB1 was recruited to bind and ubiquitinate ERR $\alpha$ at $\mathrm{K} 51$ and K68. Thus, CA promoted ERR $\alpha$ degradation (Fig. 9). In a former report, STUB1 was shown to regulate osteoclasts formation by promoting tumor necrosis factor receptor associated factor 6 degradation [56]. The bone remodeling phenotype of STUB $1^{-1-}$ mice might also attribute to decreased ERR $\alpha$ ubiquitination and degradation.

In conclusion, we have discovered that $\mathrm{CA}$ functions as the first dual-targeted small molecule against SREBP2 and ERR $\alpha$. CA inhibits RANKL-induced osteoclast formation 
and ovariectomy-induced bone loss by inhibiting the SREBP2/cholesterol/ERR $\alpha$ signal pathway. This discovery enriches the pharmacological activity of $\mathrm{CA}$ and provides an experimental evidence for the diversity function of rosemary as a food additive. CA can serve as a lead compound for pharmacological control of osteoporosis.

Acknowledgements This work was supported by the Ministry of Science and Technology of China (2019YFC1711000), the National Natural Science Foundation of China (81773957, 81421005, 81903871), the National Key Subject of Drug Innovation (No. 2017ZX09301012003), China Postdoctoral Science Foundation (2018M642380), the 111 Project (B16046). This project was also supported by the Project Program of State Key Laboratory of Natural Medicines, China Pharmaceutical University (SKLNMZZCX201820), the "Double First-Class" University Project (CPU2018GF04).

\section{Compliance with ethical standards}

Conflict of interest The authors declare that they have no conflict of interest.

Publisher's note Springer Nature remains neutral with regard to jurisdictional claims in published maps and institutional affiliations.

\section{References}

1. Manolagas SC, Jilka RL. Bone marrow, cytokines, and bone remodeling-emerging insights into the pathophysiology of osteoporosis. N Engl J Med. 1995;332:305-11.

2. Prideaux M, Findlay DM, Atkins GJ. Osteocytes: the master cells in bone remodelling. Curr Opin Pharmacol. 2016;28:24-30.

3. Roodman GD. Mechanisms of bone metastasis. N Engl J Med. 2004;350:1655-64.

4. Pittenger MF, Mackay AM, Beck SC, Jaiswal RK, Douglas R, Mosca JD, et al. Multilineage potential of adult human mesenchymal stem cells. Science. 1999;284:143-7.

5. Karsenty G. Transcriptional control of skeletogenesis. Annu Rev Genomics Hum Genet. 2008;9:183-96.

6. Ikebuchi Y, Aoki S, Honma M, Hayashi M, Sugamori Y, Khan M, et al. Coupling of bone resorption and formation by RANKL reverse signalling. Nature. 2018;561:195.

7. Zaidi M. Skeletal remodeling in health and disease. Nat Med. 2007;13:791

8. Zheng Z-G, Zhou Y-P, Zhang X, Thu PM, Xie Z-S, Lu C, et al. Anhydroicaritin improves diet-induced obesity and hyperlipidemia and alleviates insulin resistance by suppressing SREBPs activation. Biochem Pharmacol. 2016;122:42-61.

9. Derby CA, Crawford SL, Pasternak RC, Sowers M, Sternfeld B, Matthews KA. Lipid changes during the menopause transition in relation to age and weight: the Study of Women's Health Across the Nation. Am J Epidemiol. 2009;169:1352-61.

10. Jeong T-D, Lee W, Choi S-E, Kim JS, Kim H-K, Bae SJ, et al. Relationship between serum total cholesterol level and serum biochemical bone turnover markers in healthy pre-and postmenopausal women. BioMed Res Int. 2014;2014:398397.

11. Makovey J, Chen JS, Hayward C, Williams FM, Sambrook PN. Association between serum cholesterol and bone mineral density. Bone. 2009;44:208-13.

12. Yamaguchi T, Sugimoto T, Yano S, Yamauchi M, Sowa H, Chen $\mathrm{Q}$, et al. Plasma lipids and osteoporosis in postmenopausal women. Endocr J. 2002;49:211-7.
13. Curry SJ, Krist AH, Owens DK, Barry MJ, Caughey AB, Davidson KW, et al. Screening for osteoporosis to prevent fractures: US Preventive Services Task Force recommendation statement. J Am Med Assoc. 2018;319:2521-31.

14. Mandal CC. High cholesterol deteriorates bone health: new insights into molecular mechanisms. Front Endocrinol. 2015;6:165.

15. Luegmayr E, Glantschnig H, Wesolowski G, Gentile M, Fisher J, Rodan $\mathrm{G}$, et al. Osteoclast formation, survival and morphology are highly dependent on exogenous cholesterol/lipoproteins. Cell Death Differ. 2004;11:S108.

16. Sato $\mathrm{T}$, Morita I, Murota $\mathrm{S}$. Involvement of cholesterol in osteoclast-like cell formation via cellular fusion. Bone. 1998;23:135-40.

17. Grasser W, Baumann A, Petras S, Harwood H, Devalaraja R, Renkiewicz R, et al. Regulation of osteoclast differentiation by statins. J Musculoskelet Neuronal Interact. 2003;3:53-62.

18. Ruan F, Zheng Q, Wang J. Mechanisms of bone anabolism regulated by statins. Biosci Rep. 2012;32:511-9.

19. Mundy G, Garrett R, Harris S, Chan J, Chen D, Rossini G, et al. Stimulation of bone formation in vitro and in rodents by statins. Science. 1999;286:1946-9.

20. Meier CR, Schlienger RG, Kraenzlin ME, Schlegel B, Jick H. HMG-CoA reductase inhibitors and the risk of fractures. J Am Med Assoc. 2000;283:3205-10.

21. Inoue K, Imai Y. Identification of novel transcription factors in osteoclast differentiation using genome-wide analysis of open chromatin determined by Dnase-seq. J Bone Miner Res. 2014;29:1823-32.

22. Inoue K, Imai Y. Fatostatin, an SREBP inhibitor, prevented RANKL-induced bone loss by suppression of osteoclast differentiation. Biochim Biophys Acta. 2015;1852:2432-41.

23. Zheng Z-G, Zhang X, Zhou Y-P, Lu C, Thu PM, Qian C, et al. Anhydroicaritin, a SREBPs inhibitor, inhibits RANKL-induced osteoclastic differentiation and improves diabetic osteoporosis in STZ-induced mice. Eur J Pharmacol. 2017;809:156-62.

24. Jie Z, Xie Z, Xu W, Zhao X, Jin G, Sun X, et al. SREBP-2 aggravates breast cancer associated osteolysis by promoting osteoclastogenesis and breast cancer metastasis. Biochim Biophysa Acta. 2019;1865:115-25.

25. Eichner LJ, Giguère V. Estrogen related receptors (ERRs): a new dawn in transcriptional control of mitochondrial gene networks. Mitochondrion. 2011;11:544-52.

26. Gallet M, Vanacker J-M. ERR receptors as potential targets in osteoporosis. Trends Endocrinol Metab. 2010;21:637-41.

27. Wan Y. PPAR $\gamma$ in bone homeostasis. Trends Endocrinol Metab. 2010;21:722-8.

28. Wei W, Wang X, Yang M, Smith LC, Dechow PC, Wan Y. PGC1 $\beta$ mediates PPAR $\gamma$ activation of osteoclastogenesis and rosiglitazone-induced bone loss. Cell Metab. 2010;11:503-16.

29. Bonnelye E, Aubin JE. An energetic orphan in an endocrine tissue: a revised perspective of the function of estrogen receptorrelated receptor alpha in bone and cartilage. J Bone Miner Res. 2013;28:225-33.

30. Bonnelye E. Estrogen Receptor Related Receptor Alpha (ERR $\alpha)$ in skeletal tissues. Endocrinol Metab Syndr. 2016;5: 2161-1017.1000244.

31. Wei W, Schwaid AG, Wang X, Wang X, Chen S, Chu Q, et al. Ligand activation of ERR $\alpha$ by cholesterol mediates statin and bisphosphonate effects. Cell Metab. 2016;23:479-91.

32. Birtic S, Dussort P, Pierre FX, Bily AC, Roller M. Carnosic acid. Phytochemistry. 2015;115:9-19.

33. Marino S, Logan JG, Mellis D, Capulli M. Generation and culture of osteoclasts. BoneKEy Rep. 2014;3:570.

34. Hotokezaka H, Sakai E, Kanaoka K, Saito K, Matsuo K-i, Kitaura $\mathrm{H}$, et al. U0126 and PD98059, specific inhibitors of MEK, 
accelerate differentiation of RAW264. 7 cells into osteoclast-like cells. J Biol Chem. 2002;277:47366-72.

35. Xie Z, Wan X, Zhong L, Yang H, Li P, Xu X. Carnosic acid alleviates hyperlipidemia and insulin resistance by promoting the degradation of SREBPs via the 26S proteasome. J Funct Foods. 2017;31:217-28.

36. Willy PJ, Murray IR, Qian J, Busch BB, Stevens WC, Martin R, et al. Regulation of PPAR $\gamma$ coactivator $1 \alpha$ (PGC- $1 \alpha)$ signaling by an estrogen-related receptor $\alpha(E R R \alpha)$ ligand. Proc Natl Acad Sci USA. 2004;101:8912-7.

37. Tanaka Y, Nakayamada S, Okada Y. Osteoblasts and osteoclasts in bone remodeling and inflammation. Curr Drug Targets-Inflamm Allergy. 2005;4:325-8.

38. Sims NA, Martin TJ. Coupling the activities of bone formation and resorption: a multitude of signals within the basic multicellular unit. BoneKEy Rep. 2014;3:481.

39. Ghadiri-Anari A, Mortezaii-Shoroki Z, Modarresi M, Dehghan A. Association of lipid profile with bone mineral density in postmenopausal women in Yazd province. International. J Reprod Biomed. 2016;14:597.

40. Feng X, McDonald JM. Disorders of bone remodeling. Annu Rev Pathol. 2011;6:121-45.

41. Lindsay R, Gallagher JC, Kleerekoper M, Pickar JH. Effect of lower doses of conjugated equine estrogens with and without medroxyprogesterone acetate on bone in early postmenopausal women. J Am Med Assoc. 2002;287:2668-76.

42. Clemons M, Goss P. Estrogen and the risk of breast cancer. N Engl J Med. 2001;344:276-85.

43. Chung S-H, Franceschi S, Lambert PF. Estrogen and ER $\alpha$ : culprits in cervical cancer? Trends Endocrinol Metab. 2010; 21:504-11.

44. Adami HO, Persson I, Hoover R, Schairer C, Bergkvist L. Risk of cancer in women receiving hormone replacement therapy. Int $\mathrm{J}$ Cancer. 1989;44:833-9.

45. Nelson ER, Chang C-y, McDonnell DP. Cholesterol and breast cancer pathophysiology. Trends Endocrinol Metab. 2014; 25:649-55.
46. Llaverias G, Danilo C, Mercier I, Daumer K, Capozza F, Williams $\mathrm{TM}$, et al. Role of cholesterol in the development and progression of breast cancer. Am J Pathol. 2011;178:402-12.

47. Suzuki T, Miki Y, Moriya T, Shimada N, Ishida T, Hirakawa H, et al. Estrogen-related receptor $\alpha$ in human breast carcinoma as a potent prognostic factor. Cancer Res. 2004;64:4670-6.

48. Jarzabek K, Koda M, Kozlowski L, Sulkowski S, Kottler M-L, Wolczynski S. The significance of the expression of ERR $\alpha$ as a potential biomarker in breast cancer. J Steroid Biochem Mol Biol. 2009;113:127-33.

49. Stein RA, Gaillard S, McDonnell DP. Estrogen-related receptor alpha induces the expression of vascular endothelial growth factor in breast cancer cells. J Steroid Biochem Mol Biol. 2009; 114:106-12.

50. Vargas G, Bouchet M, Bouazza L, Reboul P, Boyault C, Gervais $\mathrm{M}$, et al. ERR $\alpha$ promotes breast cancer cell dissemination to bone by increasing RANK expression in primary breast tumors. Oncogene. 2019;38:950.

51. Pei H, Peng Y, Zhao Q, Chen Y. Small molecule PROTACs: an emerging technology for targeted therapy in drug discovery. RSC Adv. 2019;9:16967-76.

52. An S, Fu L. Small-molecule PROTACs: an emerging and promising approach for the development of targeted therapy drugs. EBioMedicine. 2018;36:553-62.

53. Peng L, Zhang Z, Lei C, Li S, Ren X, Chang Y, et al. Identification of New Small-Molecule Inducers of Estrogen-related Receptor $\alpha$ (ERR $\alpha$ ) degradation. ACS Medicinal Chem Lett. 2019;10:767-72.

54. Bondeson DP, Mares A, Smith IE, Ko E, Campos S, Miah AH, et al. Catalytic in vivo protein knockdown by small-molecule PROTACs. Nat Chem Biol. 2015;11:611.

55. Buckley DL, Van Molle I, Gareiss PC, Tae HS, Michel J, Noblin DJ, et al. Targeting the von Hippel-Lindau E3 ubiquitin ligase using small molecules to disrupt the VHL/HIF-1 $\alpha$ interaction. J Am Chem Soc. 2012;134:4465-8.

56. Li S, Shu B, Zhang Y, Li J, Guo J, Wang Y, et al. CHIP regulates osteoclast formation through promoting TRAF6 protein degradation. Arthritis Rheumatol. 2014;66:1854. 